\title{
Interrogation of Milk-Driven Changes to the Proteome of Intestinal Epithelial Cells by Integrated Proteomics and Glycomics
}

\author{
Sinead T. Morrin, ${ }^{\dagger}, \perp$ Rebecca A. Owens, ${ }^{\ddagger}$ Marie Le Berre, ${ }^{\S}$ Jared Q. Gerlach, ${ }^{\S}{ }^{\circledR}$ Lokesh Joshi, ${ }^{\S}$ \\ Lars Bode, $\|$ Jane A. Irwin, ${ }^{\perp}$ and Rita M. Hickey*, ${ }^{\dagger}(0)$ \\ ${ }^{\dagger}$ Teagasc Food Research Centre, Moorepark, Fermoy, P61C996, County Cork, Ireland \\ ${ }^{\ddagger}$ Department of Biology, Maynooth University, Maynooth, W23 F2H6, County Kildare, Ireland \\ ${ }^{\S}$ Glycoscience Group, Advanced Glycoscience Research Cluster, National Centre for Biomedical Engineering Science, National \\ University of Ireland Galway, H91TK33, Galway, Ireland \\ "Department of Pediatrics and Larsson-Rosenquist Foundation Mother-Milk-Infant Center of Research Excellence, University of \\ California, San Diego, La Jolla, California 92093, United States \\ ${ }^{\perp}$ Veterinary Sciences Centre, School of Veterinary Medicine, University College Dublin, Belfield, Dublin 4, D04 V1W8, Ireland \\ Supporting Information
}

\begin{abstract}
Bovine colostrum is a rich source of bioactive components which are important in the development of the intestine, in stimulating gut structure and function and in preparing the gut surface for subsequent colonization of microbes. What is not clear, however, is how colostrum may affect the repertoire of receptors and membrane proteins of the intestinal surface and the post-translational modifications associated with them. In the present work, we aimed to characterize the surface receptor and glycan profile of human HT-29 intestinal cells after exposure to a bovine colostrum fraction (BCF) by means of proteomic and glycomic analyses. Integration of label-free quantitative proteomic analysis and lectin array profiles confirmed that BCF exposure results in changes in the levels of glycoproteins present at the cell surface and also changes to their glycosylation pattern. This study contributes to our understanding of how milk components may regulate intestinal cells and prime them for bacterial interaction.
\end{abstract}

KEYWORDS: bovine colostrum, proteome, receptor, glycomics, lectin array, milk

\section{INTRODUCTION}

The mammalian intestine holds a community of trillions of microbes, collectively known as the gut microbiome, which have coevolved with the host in a mutually beneficial manner. ${ }^{1}$ It is the epithelial surface that determines the type of microbes that are able to colonize. The critical step in microbial colonization of the intestinal epithelium is the adherence of bacterial surface lectins to intestinal glycan structures. ${ }^{2}$ Understanding the influence of nutrition on the intestinal cell surface and glycan landscape is still in its infancy $\left(\right.$ reviewed $\left.^{3}\right)$. Studies have revealed, however, that certain dietary factors can influence the intestinal landscape. Highprotein diets, for instance, have been shown to up-regulate mucin expression while concurrently increasing pro- and antiinflammatory cytokines in the colonic mucosa of supplemented piglets. ${ }^{4,5}$ High protein diets can also influence brush border glycosylation and the enzymes associated with it including sucrase, lactase, glucosidase, and galactosidases. ${ }^{6}$ High-fat diets induce an increase in the sialo/sulfomucins ratio of colonic mucins in mice. ${ }^{7}$ In other studies, both fat and protein levels in the human diet have been shown to modulate intestinal glycosylation. ${ }^{8,9}$ Restriction of dietary threonine significantly inhibits synthesis of intestinal mucins ${ }^{10}$ while vitamin A supplementation impacts the expression of numerous extracellular matrix proteins (ECM) including laminin, collagen, elastin, fibronectin, and proteoglycans. ${ }^{11} \mathrm{~A}$ deficiency in vitamin $\mathrm{A}$ is detrimental to the intestinal barrier reducing levels of MUC2 and defensin-6 expression, while also enhancing MUC3, TLR2, and TLR5 expression. ${ }^{12}$

A number of studies have indicated that, as the first diet introduced to mammals, milk may have an important influence on the intestinal cell surface. ${ }^{13,14}$ Colostrum, the first milk, may be expected to have the most profound influence on the intestinal epithelium. It acts as the very first line of defense in the gut of the newborn. At this stage the intestinal epithelium is not yet fully developed and has to acquire both innate and adaptive immune defense. Colostrum contains a wide variety of antimicrobial peptides, oligosaccharides, growth factors, and immune-regulating components with anti-inflammatory and immuno-modulatory properties. ${ }^{15}$ Indeed, a shift in the glycosylation of intestinal proteins is witnessed from birth to weaning in animal models with increased terminal fucosylation and decreased sialylation, ${ }^{16,17}$ indicating the importance of milk in modulating intestinal surface properties. Angeloni et al. ${ }^{18}$ demonstrated that Caco-2 cells alter their cell surface glycan profile upon exposure to $3^{\prime}$-sialyllactose ( $\left.3^{\prime} \mathrm{SL}\right)$, one of the major oligosaccharides in milk. The expression of the sialyltransferases ST3Gal1, 2, and 4 were reduced by 2.5-, 2-, and 5-fold, respectively while ST3Gal3, 5, and 6 were

Received: November 22, 2018

Revised: January 18, 2019

Accepted: January 21, 2019

Published: January 21, 2019 
unaffected by $3^{\prime}$ SL. The subsequent reduction in $\alpha-2,3-$ and $\alpha$ 2,6-linked sialic acid coincided with a reduction in the adhesion of enteropathogenic Escherichia coli (EPEC) to the cells. ${ }^{18}$ It should be noted, however, that models such as Caco2 and HT-29 cells have limitations in that that they do not mimic the composition of the normal intestinal monolayer, which contains more than one cell type, and these cells also lack a fully formed mucus layer to separate the epithelial cell layer from the luminal content. ${ }^{19}$ However, such in vitro models are still attractive due to their reproducibility and simplicity. Furthermore, tracking the effect of a food bioactive in a cell line model allows for studies on molecular mechanisms which may be more difficult to address in vivo.

Recently, our group investigated the ability of a bovine colostrum fraction (BCF) to modulate the intestinal cell surface and, in turn, the attachment of several selected commensal organisms. ${ }^{20}$ Exposure of HT-29 cells to the $\mathrm{BCF}$ resulted in an increase in the adherence (up to 52 -fold) of a range of commensal bacteria, comprising mainly bifidobacteria. Importantly, the BCF did not correlate with enhanced adhesion of the pathogens tested. These cell surface changes are thought to be linked to the differential expression of several genes and, in particular, genes associated with glycosylation (glycosyltransferases and genes involved in the complex biosynthetic pathways of glycans) suggesting modulation of the enzymatic addition of sugars to glycoconjugates. ${ }^{20}$ While this study indicated certain genes that may be involved in modulating the phenotypic changes occurring in the HT-29 cells in response to the $\mathrm{BCF}$, genomic expression microarrays do not always estimate absolute expression levels accurately. ${ }^{21,22}$

In this study, we aimed to obtain integrated omics data sets to develop a workflow suitable for simultaneous analysis of cell surface glycans and proteins/peptides. We used a gel-free proteomic approach to monitor proteome changes in the HT29 cells after exposure to the BCF. Q Exactive Orbitrap MS was used for a full proteomic scan of the intestinal cells, and for a large-scale quantitative analysis of protein dynamics during intestinal cell-BCF exposure. Modulation of the total surface protein glycome of the HT-29 cells in response to BCF was evaluated using lectin microarray technology. Proteins with altered expression levels in response to BCF treatment were identified using both quantitative and qualitative analysis. Functional characterization was carried out, revealing gene ontology (GO) terms represented among the differentially abundant proteins.

\section{MATERIALS AND METHODS}

Generation of Bovine Colostrum Fraction. Pooled bovine colostrum (Day 1) was collected from Holstein Friesian cattle on-site at the Teagasc Food Research Centre, Moorepark (Fermoy, Cork, Ireland). The colostrum was subsequently defatted and decaseinated as previously described by Kobata et al. ${ }^{23} \mathrm{~A}$ fraction rich in oligosaccharides was isolated and characterized as previously described. ${ }^{20,24}$

Epithelial Cell Line Conditions. The human colon adenocarcinoma cell line HT-29 was purchased from the American Type Culture Collection (ATCC, Middlesex, UK). HT-29 cells were cultured in McCoy's 5A modified medium (Merck). HT-29 cells were routinely passaged in $75 \mathrm{~cm}^{2}$ tissue culture flasks in a $37{ }^{\circ} \mathrm{C}$ incubator with a humidified atmosphere $\left(5 \% \mathrm{CO}_{2}\right)$. Flasks of $80 \%$ confluency were passaged. HT-29 cells were seeded into 12 well plates (Corning, NY, USA) at a concentration of $1 \times 10^{5}$ cells per well and incubated at 37 ${ }^{\circ} \mathrm{C}$ in $5 \% \mathrm{CO}_{2}$ in a humidified atmosphere. The cells were fed every second day with McCoy's 5A modified medium supplemented with $10 \%(\mathrm{v} / \mathrm{v})$ fetal bovine serum (FBS) until $100 \%$ confluency was reached.

Epithelial Cell Line Conditions: Proteomic Preparation. HT29 cells were washed and placed in McCoy's 5A modified medium supplemented with $2 \%$ (v/v) FBS before sample exposure. After $24 \mathrm{~h}$, the cells were washed with phosphate buffered saline and treated with (filter-sterilized) $4 \mathrm{mg} / \mathrm{mL} \mathrm{BCF}$ resuspended in preheated, serum-free McCoy's 5A (0\% FBS) without phenol red. Nonsupplemented serumfree McCoy's 5A medium (without phenol red) was used as a control (NT). Biological replicates of BCF treated and control cells were prepared ( $n=3$ per condition). The plates were then incubated at 37 ${ }^{\circ} \mathrm{C}$ for $24 \mathrm{~h}$ in a humidified atmosphere $\left(5 \% \mathrm{CO}_{2}\right)$. After $24 \mathrm{~h}$, cell supernatants were collected and filtered through a $0.22 \mu \mathrm{m}$ filter to remove detached cells. The original BCF sample $(4 \mathrm{mg} / \mathrm{mL})$ was added to the nontreated cell supernatant after harvesting to ensure the control and treated supernatants contained the same background protein profile for label-free quantitative comparison and all samples were frozen in liquid nitrogen. Cells from matching wells were washed three times with PBS to remove any residue and the cells were harvested and immediately frozen in liquid nitrogen and stored at -70 ${ }^{\circ} \mathrm{C}$ for proteomic analysis.

Protein Mass Spectrometry. Protein Extraction. BCF-treated and control HT-29 cells were suspended in lysis buffer $(100 \mathrm{mM}$ Tris$\mathrm{HCl}, 50 \mathrm{mM} \mathrm{NaCl}, 20 \mathrm{mM}$ EDTA, 10\% (v/v) glycerol, $1 \mathrm{mM}$ PMSF, $1 \mu \mathrm{g} / \mu \mathrm{L}$ pepstatin $\mathrm{A}, \mathrm{pH} 7.5)$ and briefly sonicated using an MS72 probe $(3 \times 10 \mathrm{~s}, 20 \%$ power $)$ to release proteins for label-free quantitative (LFQ) comparative proteomics. ${ }^{25}$ Cell lysates were incubated in ice for $1 \mathrm{~h}$ and then clarified using centrifugation. For culture supernatants, proteins were concentrated using Amicon Ultra centrifugal filters ( $3 \mathrm{kDa}$ molecular weight cutoff, MWCO). Protein precipitation from cell lysates and culture supernatants was carried out using trichloroacetic acid (TCA; final $15 \%(\mathrm{w} / \mathrm{v}))$ and samples were stored at $4{ }^{\circ} \mathrm{C}$ for $20 \mathrm{~min}$. Precipitated proteins were pelleted by centrifugation at $12,000 \mathrm{RCF}$ for $10 \mathrm{~min}$ at $4{ }^{\circ} \mathrm{C}$ and pellets were washed twice with ice-cold acetone. Protein pellets were resolubilized in UT buffer ( $8 \mathrm{M}$ urea, $2 \mathrm{M}$ thiourea, 0.1 M Tris-HCL ( $\mathrm{pH} 8$ )) and a Bradford assay was employed to determine the protein concentration of each sample prior to digestion.

Protein Digestion. Protein samples were diluted 6-fold with 50 $\mathrm{mM}$ ammonium bicarbonate, reduced and alkylated, with dithiothreitol (DTT; $5 \mathrm{mM}$ final) and iodoacetamide (IAA; $15 \mathrm{mM}$ final), respectively. Sequencing grade trypsin $(1 \mu \mathrm{g}$ per $25 \mu \mathrm{g}$ sample protein) and ProteaseMax surfactant $(0.01 \%(\mathrm{w} / \mathrm{v})$ final $)$ were added to each sample and incubated overnight at $37{ }^{\circ} \mathrm{C}$. A cleanup of digested samples to remove salt was performed prior to analysis using Zip Tips with C18 resin (Millipore). Desalted peptide mixtures were then analyzed using a Thermo Fisher Q-Exactive mass spectrometer coupled to a Dionex RSLC nano with an EasySpray PepMap C18 column $(50 \mathrm{~cm} \times 75 \mu \mathrm{m}, 2 \mu \mathrm{m}$ particles). Liquid chromatography gradients were run from $14 \%$ to $35 \%$ B (A: $0.1 \%(v / v)$ formic acid, B: $80 \%(\mathrm{v} / \mathrm{v})$ acetonitrile, $0.1 \%(\mathrm{v} / \mathrm{v})$ formic acid) over $2 \mathrm{~h}$, and data was collected using a Top 15 method for MS/MS scans. ${ }^{26}$

Data Analysis. Label-free quantitative proteomic analysis was performed using MaxQuant (version 1.5.3.30), with MaxLFQ algorithm included for protein ratio characterization. ${ }^{27}$ Protein identification was performed by searching against a protein database consisting of the Homo sapiens proteome (UniProtKB, downloaded June 2017). This was appended with a Bos taurus proteome database for culture supernatant analysis to account for the presence of BCFderived proteins (UniProtKB, downloaded June 2017). The false discovery rate (FDR) was set to $1 \%$ at both the peptide and the protein level, with a reverse database search used. Proteins were filtered to exclude single peptide identifications and proteins matching a reverse or a contaminants database. Proteins were retained for analysis only if detected in at least 2 biological replicates from either the control or treated group. Perseus (v 1.5.4.0) was used for statistical analysis, with quantitative results composed of proteins with a significant change in abundance ( $p<0.05$ (Student's $t$ test), fold change $\geq 1.5$ ). Qualitative results were based on unique protein 
detection in at least 2 biological replicates in either the control or the treated samples, with absence of detection in all replicates of the alternate condition. Proteins exclusively matching the B. taurus database, or detected in qualitative analysis of the BCF treatment, were identified and excluded from functional analysis of the HT-29 secretome. Functional enrichment analysis of proteins was performed using the application DAVID (https://david.ncifcrf.gov/) and UniProtKB (https://www.uniprot.org/), whereby the data set was searched under Gene Ontology (GO) ${ }^{28}$ Quantitative and qualitative results were combined prior to functional characterization.

Epithelial Cell Line Preparation, Surface Protein Extraction, and Fluorescent Labeling. Prior to sample exposure, the cells were washed and placed in 2\% FBS McCoy's media. After $24 \mathrm{~h}$, the cells were washed with phosphate buffered saline and treated with (filter sterilized) $4 \mathrm{mg} / \mathrm{mL}$ BCF resuspended in preheated serum-free McCoy's 5A (0\% FBS). Nonsupplemented serum-free McCoy's 5A medium was used as a control (NT). The plates were then incubated at $37^{\circ} \mathrm{C}$ for $24 \mathrm{~h}$ in a humidified atmosphere $\left(5 \% \mathrm{CO}_{2}\right)$. Cells were harvested by scraping. Surface proteins were extracted directly from the pellet of HT-29 cells using a hydrophobic protein isolation kit (Mem-PER, ThermoFisher Scientific, Dublin, Ireland). Proteins were labeled with DyLight $550 \mathrm{~N}$-hydroxysuccinimide (NHS) ester following the manufacturer's suggested protocol. Excess dye was removed by repeated buffer exchange with a $3 \mathrm{kDa}$ MWCO filtration unit (Amicon Ultra, Merck-Millipore, Cork, Ireland).

Construction of Lectin Microarrays and HT-29 Profiling. Microarrays were constructed as previously described and consisted of 50 lectins with reported carbohydrate binding specificities (Table S1). ${ }^{29,30}$ Each feature was printed on Nexterion Slide H microarray slides in replicates of six and eight replicate subarrays were printed per slide. After printing, lectin performance was tested by incubation with fluorescently labeled glycoprotein standards. ${ }^{29}$ The lectin microarrays were stored with desiccant at $4{ }^{\circ} \mathrm{C}$ until use. Lectin microarrays were allowed to equilibrate to room temperature (RT) prior to use. Fluorescently labeled surface proteins were interrogated in the dark using an eight well gasket slide and incubation cassette system (Agilent Technologies, Cork, Ireland) as previously described. ${ }^{29,30}$ Two labeled protein samples of the control (nontreated) and protein from cells treated with $4 \mathrm{mg} / \mathrm{mL}$ BCF were titrated $(1-10 \mu \mathrm{g} / \mathrm{mL}$ in Tris-buffered saline (TBS; $20 \mathrm{mM}$ Tris- $\mathrm{HCl}, 100 \mathrm{mM} \mathrm{NaCl}, 1 \mathrm{mM}$ $\mathrm{CaCl}_{2}, 1 \mathrm{mM} \mathrm{MgCl}$, $\mathrm{pH} 7.2$ ) with $0.05 \%$ Tween 20 (TBS-T)) on the lectin microarrays for optimal signal-to-noise ratio. A concentration of $1 \mu \mathrm{g} / \mathrm{mL}$ in TBS-T was selected for all fluorescently labeled samples. Bovine asialofetuin (Sigma-Aldrich) labeled with Alexa Fluor 555 NHS ester was included in one subarray on each microarray slide $(0.5$ $\mu \mathrm{g} / \mathrm{mL}$ in TBS-T) to verify the presence and retained function of the printed lectins during each experiment. Microarrays were dried by centrifugation ( $450 \mathrm{RCF}, 5 \mathrm{~min}, 10^{\circ} \mathrm{C}$ ) and scanned immediately in an Agilent G2505B microarray scanner using the Cy3 channel (532 $\mathrm{nm}$ excitation, $80 \%$ PMT, $5 \mu \mathrm{m}$ resolution).

Data Extraction, Hierarchical Clustering, and Statistical Analysis of Lectin Microarrays. Data extraction and graphical representation was performed as previously described. ${ }^{29,30}$ Data were normalized to the mean total intensity value of three replicate microarray slides and binding data were presented in bar charts of relative average intensity values with one standard deviation of experimental replicates $(n=3 ; 18$ total data points per probe). Heat mapping (color gradation set from 0 to 50,000 RFU) and unsupervised hierarchical clustering of normalized data (lectins only, complete linkage, Euclidean distance) were performed in Morpheus (Broad Institute, https://software.broadinstitute.org/ morpheus/). Significant differences between individual lectin responses for each triplicate sample type were determined by paired, two-tailed Student's $t$ test in Excel (Microsoft, v 2013). Differential lectin responses which demonstrated $p \leq 0.05$ and also qualified with a minimum intensity of 1000 RFU (approximately $5 \times$ local background, GSL-I-A4 $(p=0.0229)$, DSA $(p=0.0403)$, RCA-I $(p$ $=0.0129)$, AMA $(p=0.0098)$, and MPA $(p=0.0152))$ were retained for principal component analysis. Principal components were calculated in Minitab (v 17) and the first two components plotted for all replicates.

\section{RESULTS AND DISCUSSION}

The extracellular membrane proteins of the epithelial cell surface are densely covered with diverse glycan chains. In order to produce the range of glycan structures found on proteins, individual cells must synthesize the glycans with the required sequence. The metabolic pathways that are responsible for this process include the production of a series of precursors from monosaccharides, the nucleotide sugars; sugar transporters that make sure that the necessary intermediates are available in the cell to produce the precursors; glycosyltransferases, which transfer the sugars to the acceptor protein to make the relevant glycan structure; plus a number of other proteins which participate in the formation of the final glycoprotein structure designed for a particular biological function. ${ }^{31}$ The absence or presence of any of these factors will define the nature of the glycans that can be synthesized by a cell. The glycans which are attached to epithelial proteins are highly heterogeneous due to the diversity of glycotransferases and glycosidases being expressed and are subject to changes by the external environment. Thus, alterations in the external environment such as diet may affect the expression at gene or protein level and will affect these oligosaccharide chains and, ultimately, the overall glycosylation pattern. ${ }^{32}$ Such changes in glycosylation may be very important, as terminal glycan epitopes are suggested as being responsible for the selection of our commensal microbiota, resulting in distinct communities. ${ }^{33}$

The HT-29 colon cell line is extensively utilized as a model of the gastrointestinal tract and is commonly used as an in vitro intestinal model of bacterial colonization. ${ }^{34,35}$ It should be noted that HT-29 cells are derived from a colic tumor, and it has been shown that carcinogenesis affects glycosylation. ${ }^{36}$ Nevertheless, HT-29 cells do display classical characteristics that model small intestinal absorptive epithelial cells upon reaching confluence ${ }^{37}$ and are a useful indicator of the structural landscape of the intestinal epithelium. Recent studies have demonstrated that HT-29 membrane glycosylation is a sensitive sensor of the cell's extracellular environment and this cell line can be used to monitor glycan changes induced by microbial and dietary compounds. ${ }^{19}$ Previously, we demonstrated that a bovine colostrum fraction (BCF) modulated the HT-29 colonic epithelial cell surface leading to significant increases in the colonization of several health-promoting strains. ${ }^{20}$ Transcriptomic studies revealed that a number of genes associated with glycosylation were differentially regulated in response to BCF. However, transcriptomic studies only reveal the initial draft of the final landscape of proteins actually produced. The proteome varies widely from the genetic transcript, due to dynamics of protein synthesis and degradation, ${ }^{38}$ as well as RNA splicing and post-translational modifications creating proteins of different functionalities from those of its original gene transcript. Therefore, to determine how the BCF was influencing the HT-29 cells, proteomic and lectin array analyses were performed on the cells after BCF treatment.

Quantitative Intracellular Proteome Analysis of HT29 cells after BCF Treatment. From LC-MS/MS analysis, a total of 3370 intracellular proteins were identified between the control (nontreated) and BCF-treated HT-29 cells across the three sets of biological replicates (Figure 1a). A 1.5-fold increase or decrease in the level of protein abundance was used 
(A)

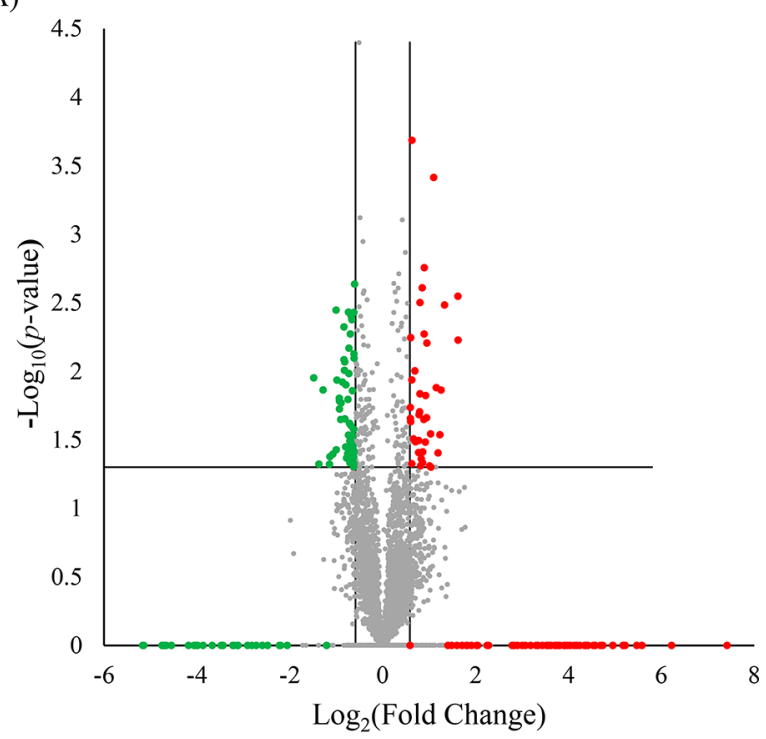

(B)

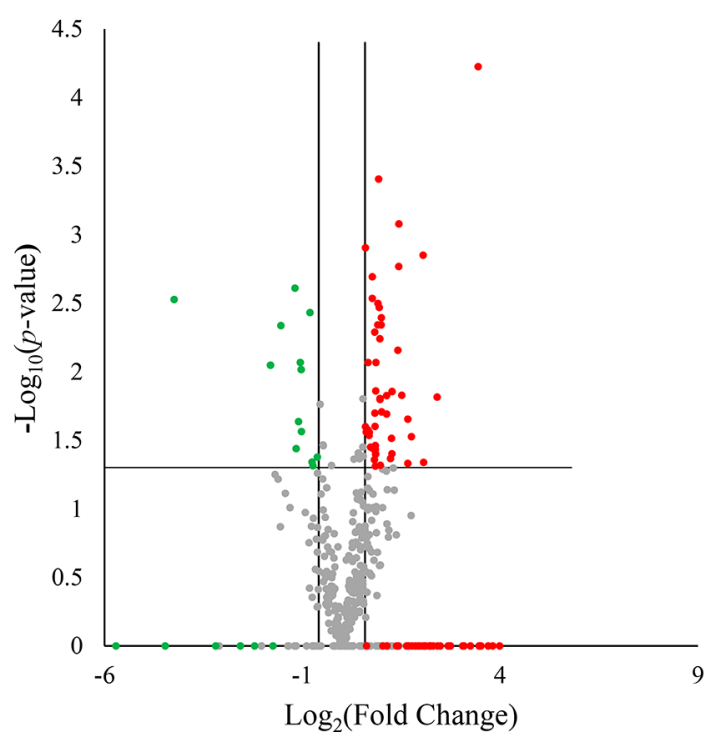

Figure 1. Volcano plots displaying quantitative and qualitative changes in (A) intracellular and (B) extracellular proteins following BCF treatment. Proteins with a significant quantitative or qualitative change in abundance are shown in red (increased abundance) and green (decreased abundance). For qualitative changes the predicted minimum fold change was calculated for each protein relative to the detection limit cutoff $\left(-\log _{10}(p\right.$-value $)=0$, red/green $)$. The detection limit cutoff was set as the mean +2 standard deviations of the lowest detectable intensity value from the full data set of each replicate in MaxQuant analysis. ${ }^{92}$ The horizontal line represents a $p$-value of 0.05 and the vertical lines indicate the fold change (fc) cutoff of 1.5.

as a benchmark for potential physiologically significant changes $(p<0.05)$ which resulted in 96 differentially abundant proteins being defined, with 40 proteins increasing and 56 decreasing in abundance following the BCF treatment. Qualitative analysis revealed a further 59 proteins uniquely detected after BCF treatment of the HT-29 cells, while 32 proteins were no longer detected after treatment (Table S2). Functional annotation and GO analysis of the differentially abundant proteins was carried out using DAVID, a high throughput bioinformatic analysis tool, to investigate functional enrichment in the altered proteome. $^{39}$ The upregulated and uniquely detected proteins were grouped and, according to the GO analysis of DAVID, were mainly involved in 21 biological processes (BP), 12 cellular components (CC), and 2 molecular functions (MF). Considering the BP category, 12 of the 21 were significantly enriched $(p<0.05)$ and included GO annotations such as negative regulation of cytokine production, glycosylation, single-organism carbohydrate metabolic process, and glycoprotein metabolic process (Figure 2a). Seven cellular components were significantly enriched, including the integral component of membrane, mitochondrial part, mitochondrial membrane, and organelle inner membrane. Only calciumdependent phospholipid binding from the MF category was deemed significant $(p<0.05)$. The down-regulated and proteins not detected after treatment with BCF were also grouped and analyzed for biological function, cellular location, and molecular function. Considering the BP category, 39 were identified of which 16 were significant: cytoskeleton organization, negative regulation of cellular component organization, cell projection assembly, and regulation of epidermal cell differentiation (Figure 2b). The cytoskeleton, actin filament bundle, actomyosin, and cytoskeletal part were the only CC terms identified of significance from the 8 listed. No MFs were identified for the down-regulated/undetected group.

Quantitative Extracellular Proteome Analysis of HT29 Cell Supernatants after BCF Treatment. A total of 524 extracellular proteins were identified in the culture supernatant of HT-29 cells between both the control (nontreated) and the BCF-treated HT-29 cells from the three sets of biological replicates (Figure $1 \mathrm{~b}$ ). After removing bovine proteins from the results, quantitative analysis revealed 51 extracellular proteins which had significantly increased levels after exposure to the BCF and 13 which were significantly decreased in abundance (fold change $\geq 1.5$-fold, $p<0.05$ ). Six proteins were no longer detectable extracellularly after BCF treatment while 37 proteins were uniquely identified in the BCF-treated culture supernatants. The differentially produced proteins were again analyzed using DAVID software to identify enriched GO annotations (Table S3). The proteins with increased abundance that were uniquely detected following BCF treatment were grouped and analyzed under the three functional classifications above (BP, CC, and MF). In the $\mathrm{BP}$ category, 24 processes were revealed, of which 12 were significantly enriched including nucleic acid metabolic process, nucleobase-containing compound metabolic process, negative regulation of nucleobase-containing compound metabolic process, and negative regulation of organelle organization (Figure 3a). In the CC category, 5 of 13 detected were found to be significant and involved in a spliceosomal complex, cellcell adherent junction, nucleus, and nuclear lumen. In the MF category, 3 of 5 functions detected were significant and were associated with RNA binding, cadherin binding and protein binding involved in cell-cell adhesion. For the proteins with lower abundance or that were undetectable following BCF treatment, $10 \mathrm{BPs}, 10 \mathrm{CCs}$, and $3 \mathrm{MF}$ were significantly enriched. The BPs significantly detected were the sulfur compound catabolic process, macromolecule catabolic process, chondroitin sulfate proteoglycan metabolic process, and protein metabolic process (Figure 3b). The CC locations detected were associated with vacuolar lumen, intracellular organelle lumen, vacuole, and cytoplasmic vesicle while the three significant MFs detected were involved in hydrolase 
(A)

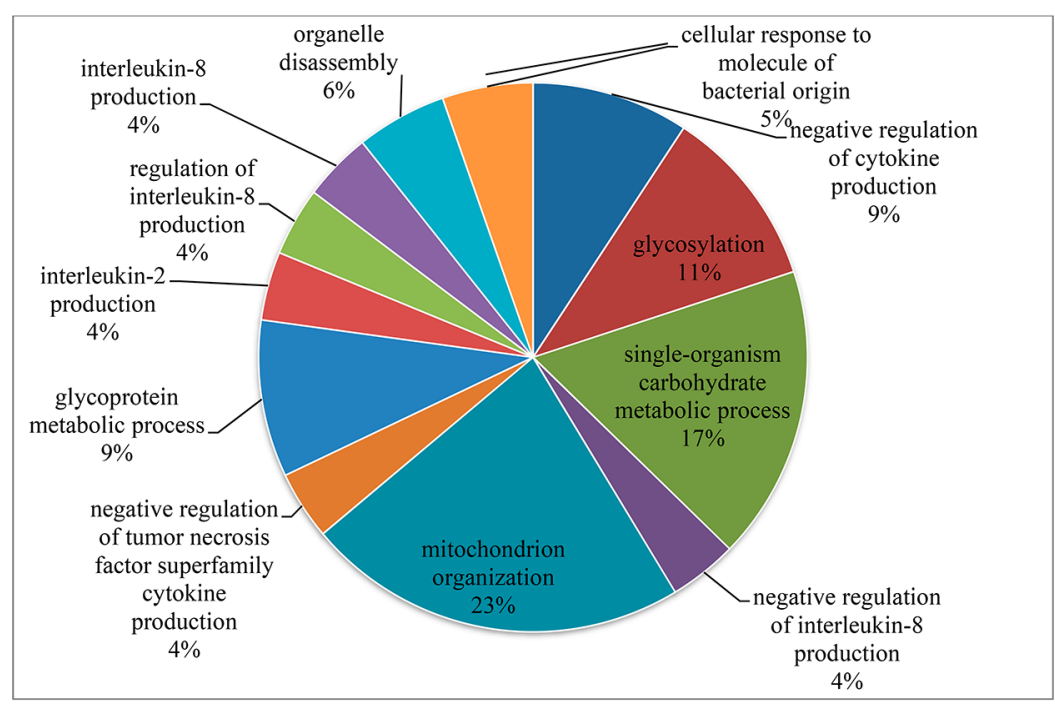

(B)

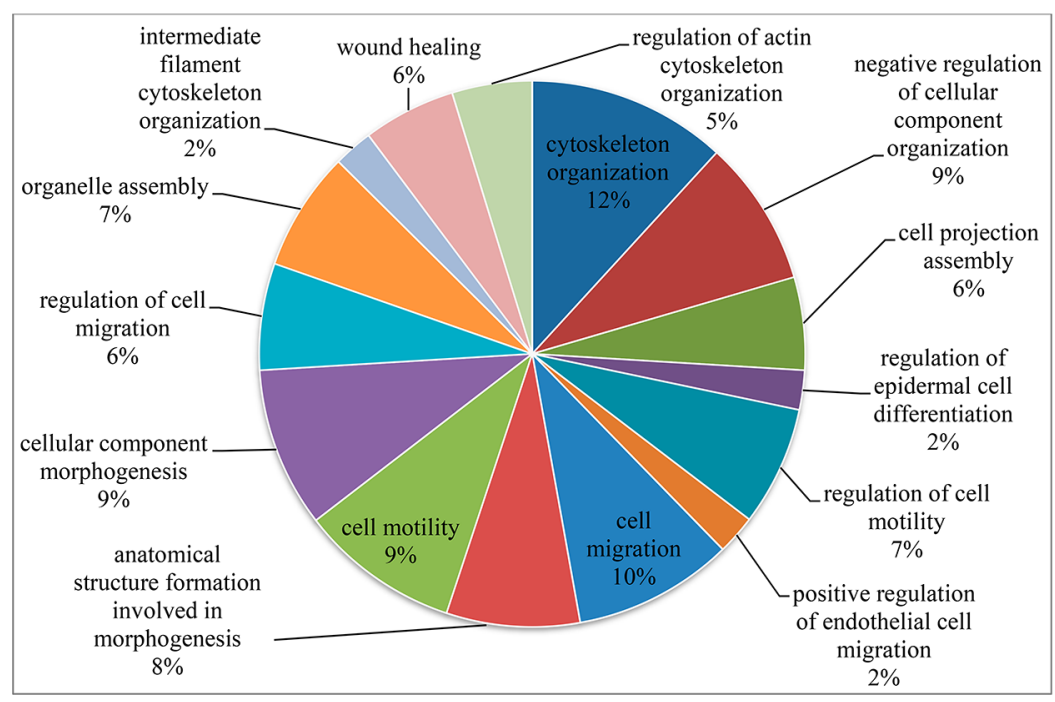

Figure 2. (Based on Table S2) Pie chart demonstrating distribution of the intracellular proteins after LC-MS/MS analysis of HT-29 cells after exposure to the bovine colostrum fraction (BCF). The proteins were distributed according to their biological process using DAVID bioinformatics resources. The proteins were classified by their corresponding gene names: (A) upregulated and uniquely detected proteins, and (B) downregulated and undetected proteins. Enriched biological processes with $p<0.05$ (Student's $t$ test) are shown.

activity, protein heterodimerization activity, serine-type peptidase activity, and hydrolyzing O-glycosyl compounds. The latter is of interest given that alteration of glycan chains through the action of glycosidases such as O-glycosidases may have an important role in the overall cell surface glycosylation pattern. $^{31}$

Glycoprotein Analysis of HT-29 Cells after BCF Treatment. The abundance of 51 proteins with putative glycosylation sites were altered in the BCF-treated HT-29 cells (Table 1). Those involved in carbohydrate metabolism included $N$-acetylglucosamine-6-sulfatase (GNS) which is required for the lysosomal degradation of the glycosaminoglycans ${ }^{40}$ heparan sulfate and keratan sulfate. This enzyme, which was no longer detectable in the extracellular fractions following BCF treatment, removes sulfate from the GAGs when the sugar $\mathrm{N}$-acetylglucosamine-6-sulfate is located at the end. This may imply that after BCF treatment, more terminal moieties of intact $\mathrm{N}$-acetylglucosamine-6-sulfate are present on the cell surface. Hexosaminidase subunits alpha and beta (HexA and HexB) have essential roles in the hydrolysis of GlcNAc and GalNAc residues from glycosphingolipids such as ganglioside GM2. Levels of HexA and HexB were reduced in the extracellular fraction of the BCF-treated cells by 1.7 -fold and 3.5-fold, respectively, which may suggest reduced hydrolysis of GlcNAc and GalNAc after BCF treatment. Many bacteria are known to interact with GM2 (https://sugarbind.expasy.org/), and commensals such as Bfidobacterium bifidum EB102 have been shown to bind to gangliotriaosylceramide (asialoGM2). ${ }^{41}$ Iduronidase, alpha-L (IDUA) hydrolyses the glycosidic bond between the terminal L-iduronic acid (IdoA) and the second sugar of $\mathrm{N}$-acetylgalactosamine (GalNAc)-4sulfate/ $\mathrm{N}$-sulfo-D-glucosamine (GlcNS)-6-sulfate, which are the major constituents of dermatan/heparan sulfate. ${ }^{42}$ Iduronidase, alpha-L (IDUA), is essential for the breakdown of glycosaminoglycans (GAGs). Again, while this enzyme was found in the control, it was not detected in the extracellular 
(A)

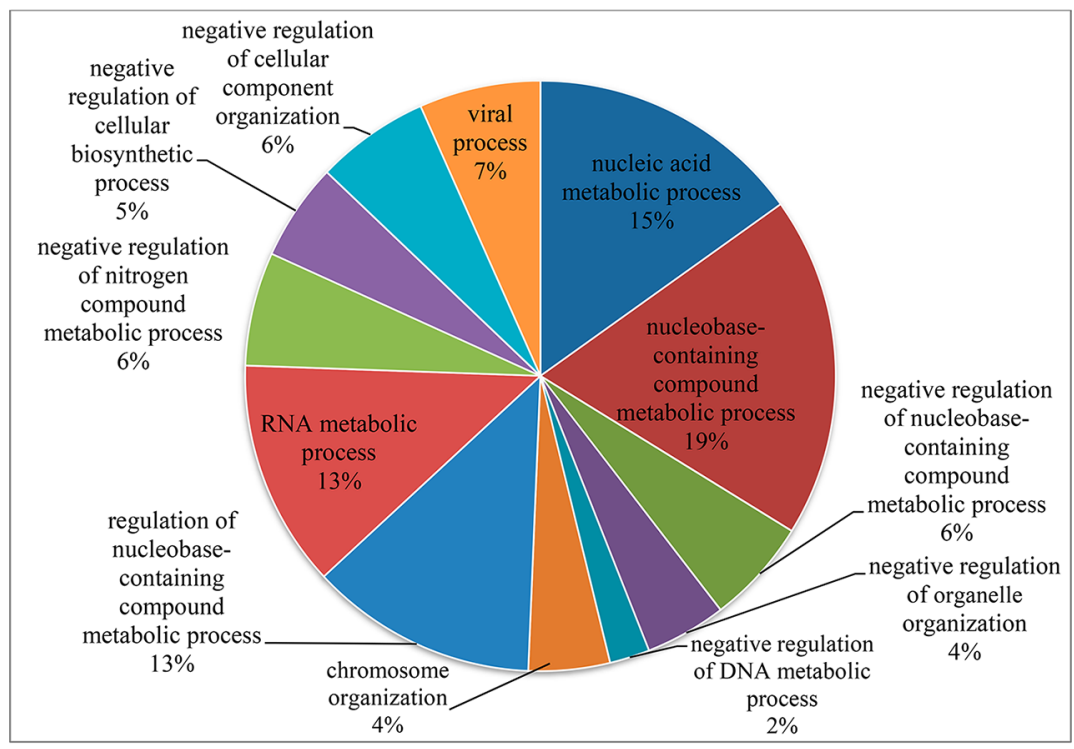

(B)

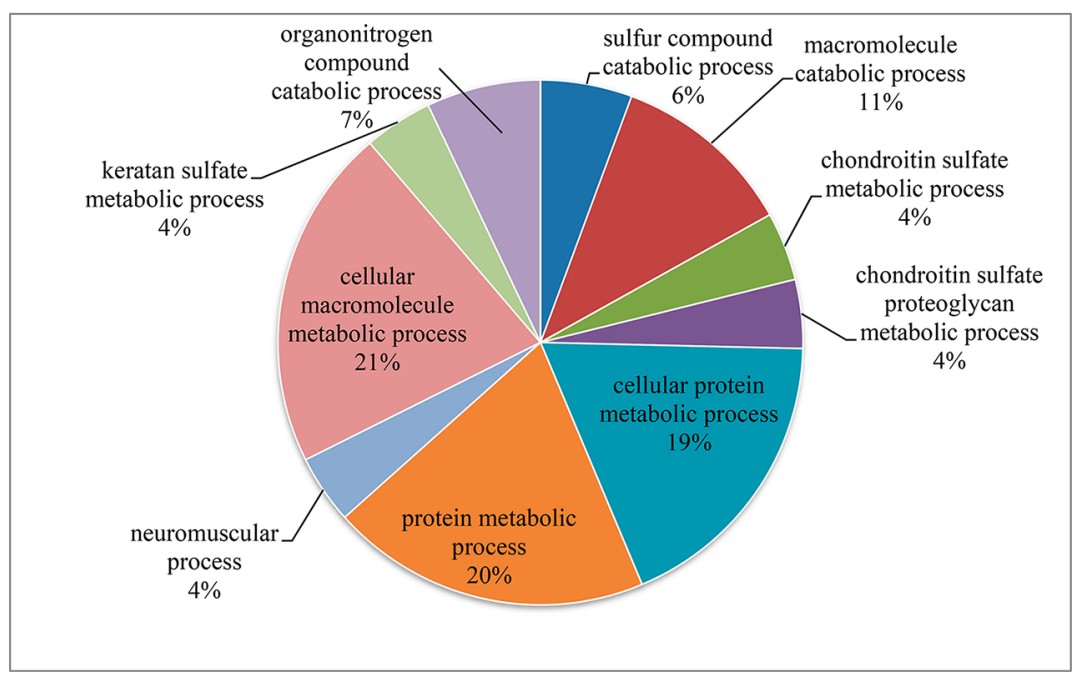

Figure 3. (Based on Table S3) A pie chart demonstrating distribution of the extracellular proteins after LC-MS/MS analysis of HT-29 cells after exposure to the bovine colostrum fraction (BCF). The proteins were distributed according to their biological process using DAVID bioinformatics resources. The proteins were classified by their corresponding gene names: (A) upregulated and uniquely detected proteins, and (B) downregulated and undetected proteins. Enriched biological processes with $p<0.05$ (Student's $t$ test) are shown.

fraction of the BCF-treated cells suggesting an increased abundance of intact heparan sulfate on the cell surface. Heparan sulfate (HS) proteoglycans are known receptor targets of both Gram-negative and Gram-positive bacteria ${ }^{43}$ and consist of repeating disaccharide units of GlcNAc and hexuronic acid residues.

The extracellular matrix (ECM) provides a network of proteins surrounding cells and is found in all mammalian tissues. The ECM is composed of two main classes of macromolecules: proteoglycans (PGs), such as heparan sulfate, and fibrous proteins such as are laminins, fibronectins elastins, and collagens. ${ }^{44}$ These proteins may provide numerous binding sites for bacterial adhesion. Procollagen-lysine,2oxoglutarate 5-dioxygenase 1 (PLOD1) is an ECM protein that catalyzes the hydroxylation of lysine residues in collagen alpha chains and is essential for normal assembly and cross- linking of collagen fibrils. PLOD1 was reduced in the extracellular fraction of the BCF-treated cells by 2.0 -fold suggesting a change in collagen assembly. Most pathogens associated with the gastrointestinal tract have the capacity to bind and degrade collagen(s) to facilitate their adherence to and invade host tissues. ${ }^{45}$ Interestingly, bioinformatic analysis of the B. bifidum S17 genome revealed proteins that contain collagen triple helix repeat domains, suggesting that bifidobacteria may be able to interact with collagen but this has yet to be confirmed. ${ }^{46}$ Lactobacillus fermentum 3872 was also shown to competitively reduce Campylobacter jejuni binding to type I collagen using ELISA plates. The phosphatidylinositol glycan anchor biosynthesis class $\mathrm{O}(\mathrm{PIGO})$ gene provides information for producing one part of an enzyme called GPI ethanolamine phosphate transfer 3 (GPI-ET3). The GPI-ET3 enzyme is involved in a number of steps that produce a molecule called a 


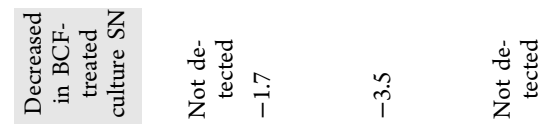

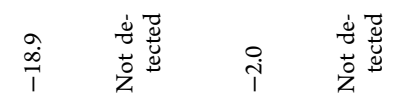

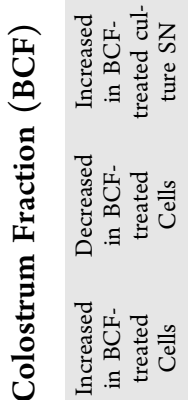

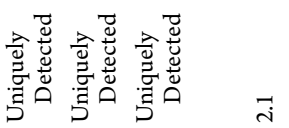

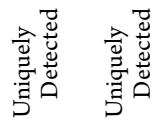

章 竞

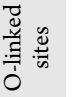

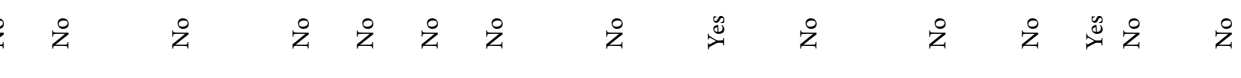

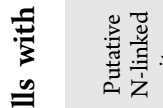

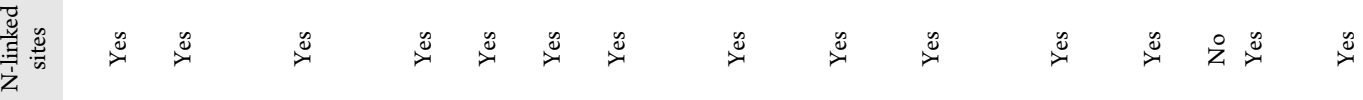

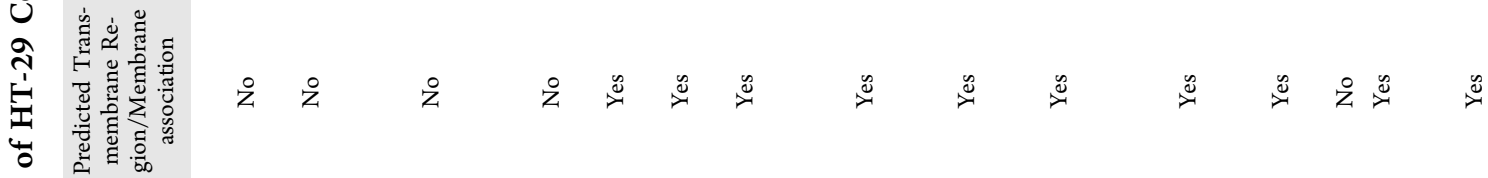
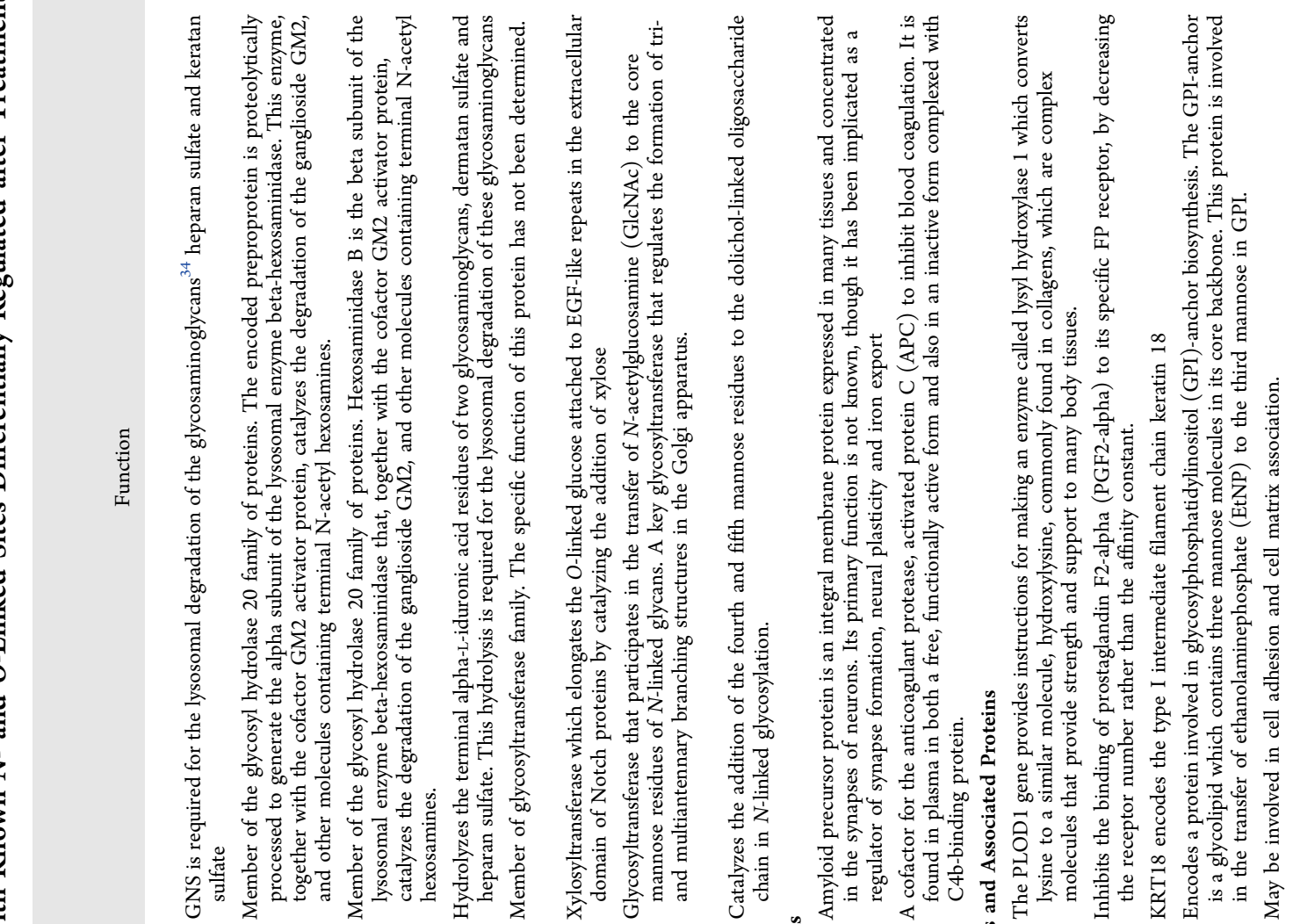

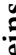

产

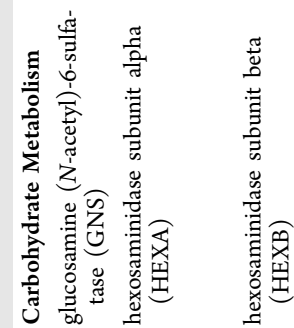

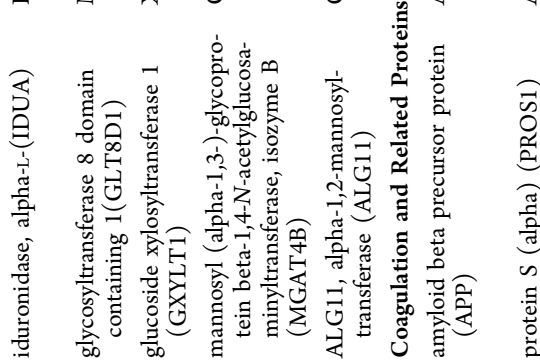

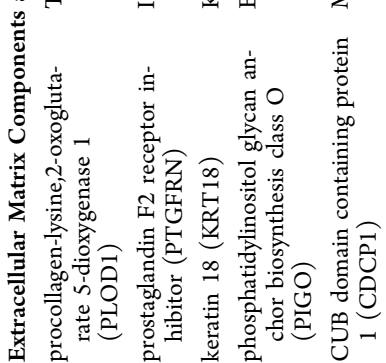




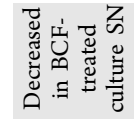

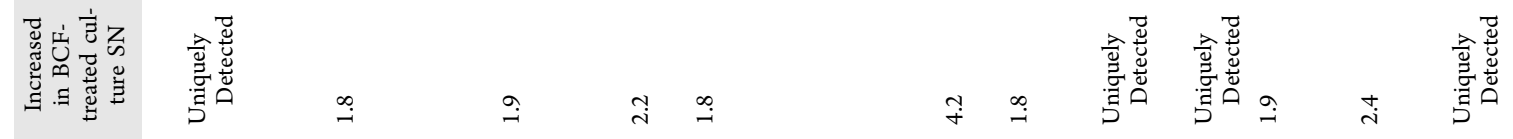

III

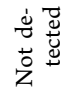

密䓀

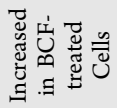

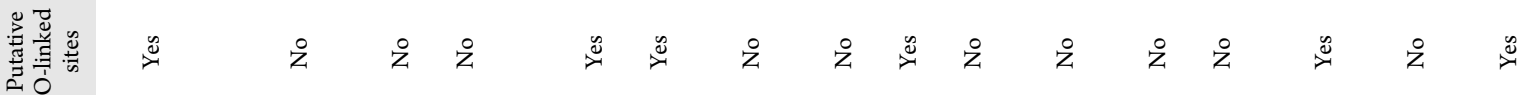

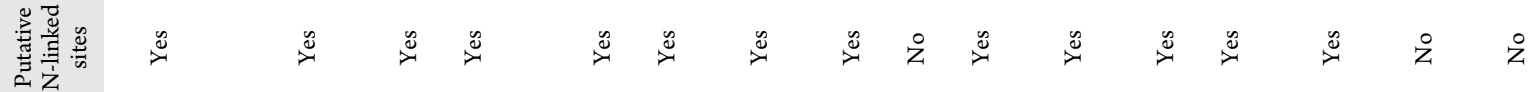

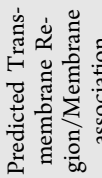

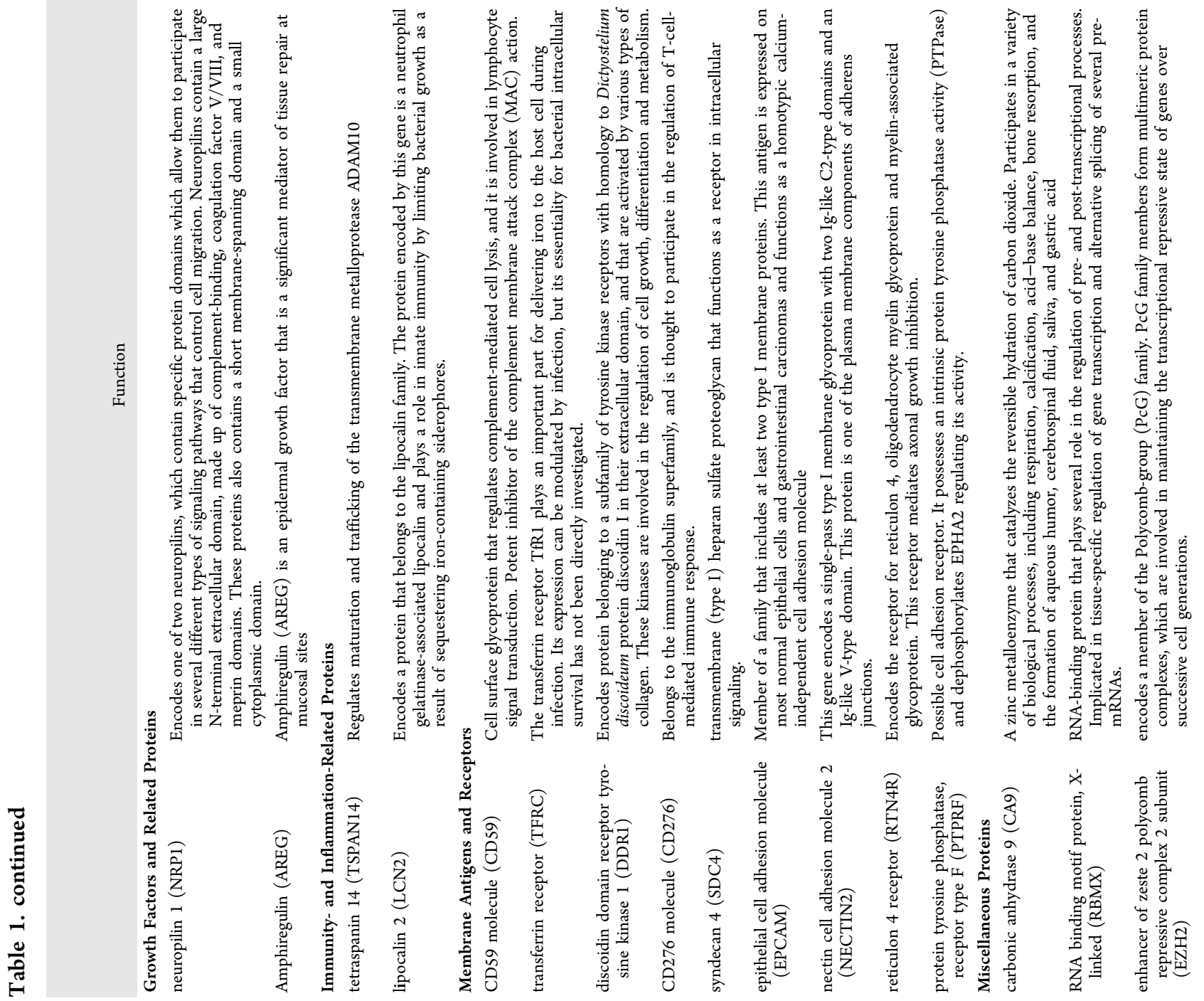




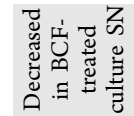

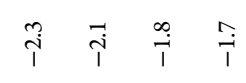

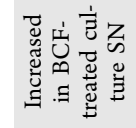

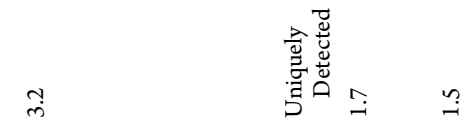

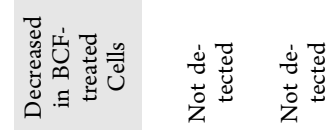

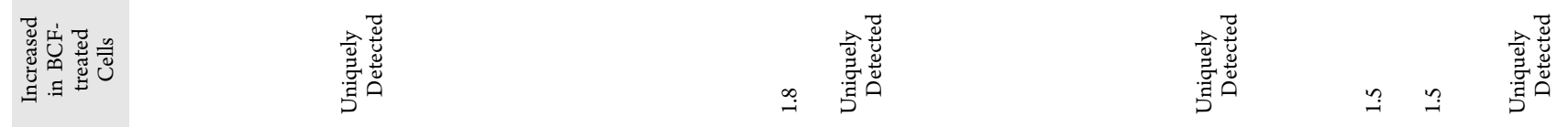

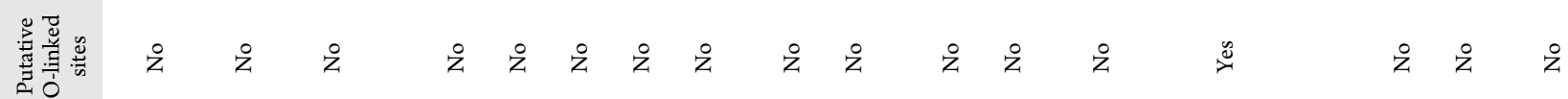

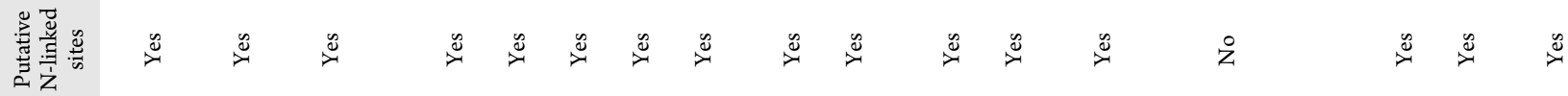

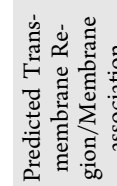

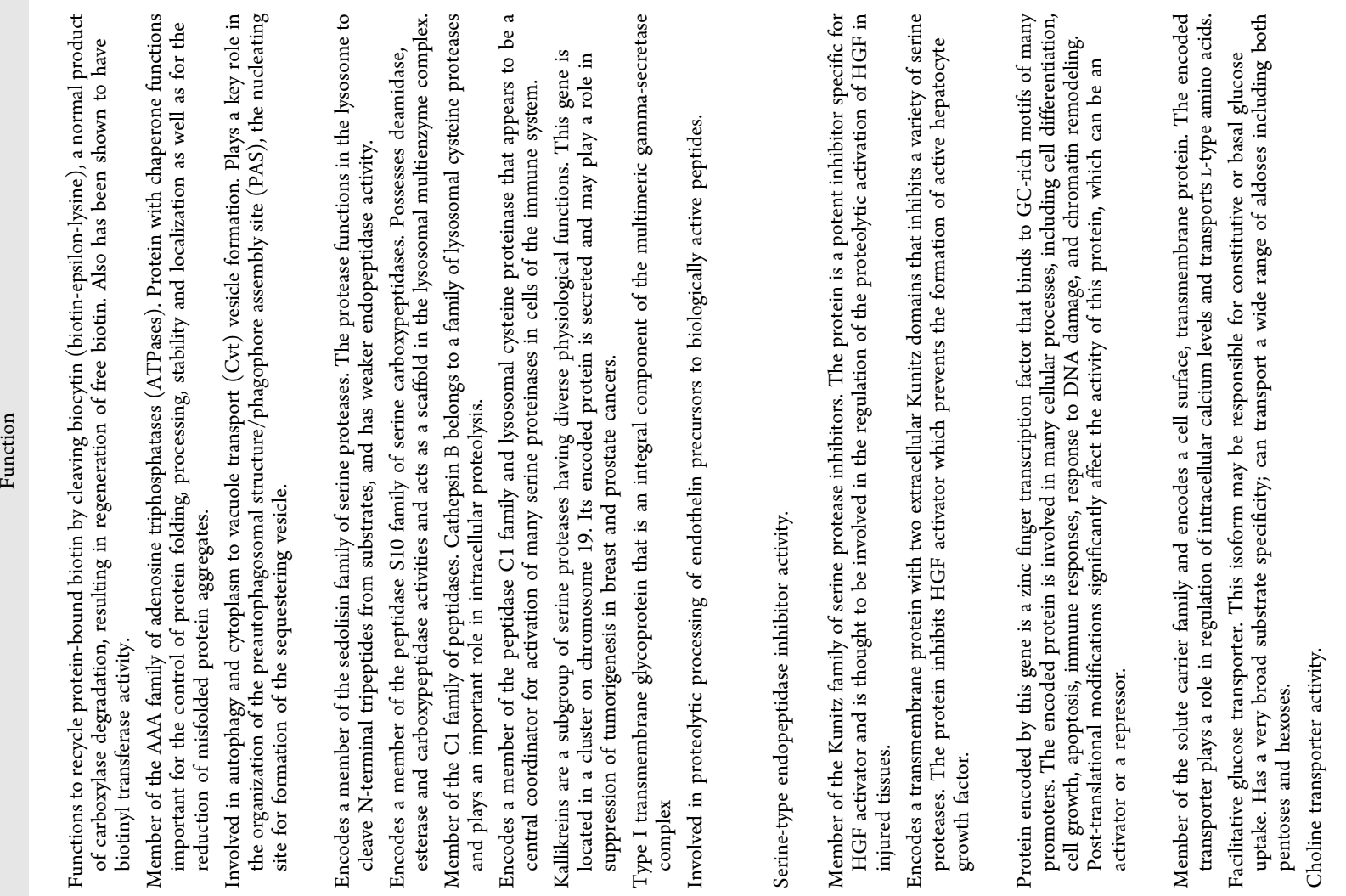

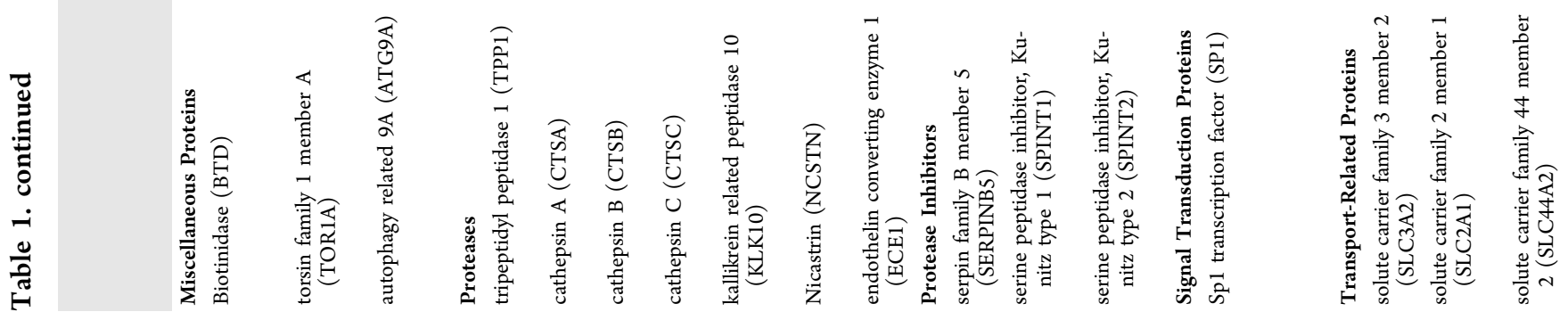




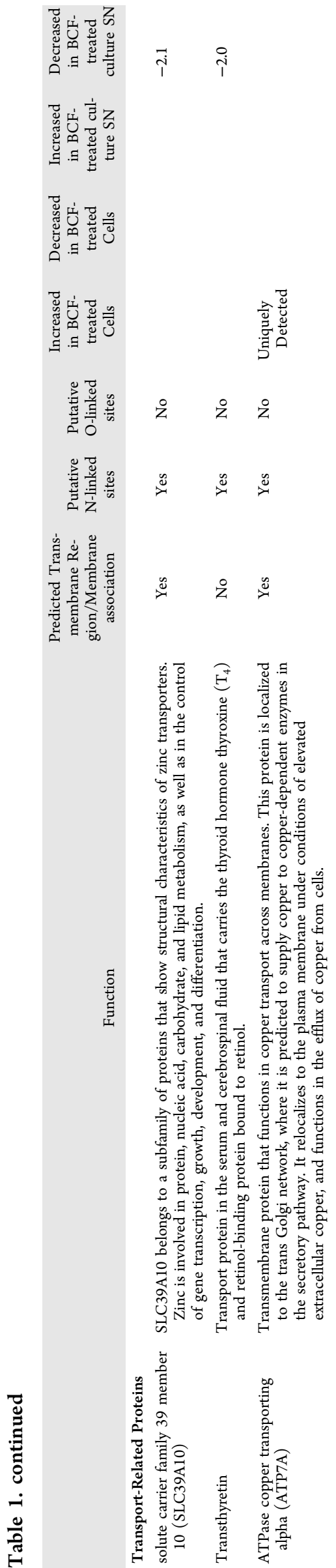

glycosylphosphosphatidylinositol (GPI) anchor. ${ }^{47}$ GPI-anchored proteins play a wide variety of physiological roles, as enzymes, cell surface antigens, signaling receptors, cell adhesion, and migration molecules. ${ }^{48,49}$ Bacteria are also known to interact with the GPI anchor, but to date, this interaction has been specific to bacterial toxins. ${ }^{50,51}$ Interestingly, PIGO was uniquely detected in the intracellular fraction of the BCF-treated cells.

Changes in the expression of membrane antigens and receptors were also evident in the BCF-treated cells. CD59 is a GPI-anchored protein with regulatory properties in activating cascades of the complement system and is well recognized for its very efficient role in defense against pathogens such as bacteria, viruses, and parasites. ${ }^{52}$ CD59 levels were increased $(2.2$-fold $)$ in the extracellular fraction of BCF treated cells. Syndecan 4 (SDC4) was up-regulated in extracellular fraction (4.2-fold) of BCF-treated cells. SDC4 is a transmembrane heparan sulfate proteoglycan. As mentioned, HS moieties are involved in the adherence of a number microorganisms. This ranges from the normal human microbiota including Lactobacillus, $^{53}$ to various pathogenic bacteria, viruses, and parasite. ${ }^{54}$ The extracellular domain of syndecan- 4 can be shed from the cell surface ${ }^{55}$ and increased levels in the supernatant after BCF treatment may indicate shedding.

Receptor-type protein tyrosine phosphatases (RPTPs) are a family of integral cell surface proteins that have intracellular protein tyrosine phosphatase activity, and extracellular domains with sequence homology to cell adhesion molecules. The R2A subfamily members of RPTPs are characterized by the presence of immunoglobulin and fibronectin type III domains in their extracellular domains, and tandem protein tyrosine phosphatases domains in their intracellular domain. ${ }^{56}$ Subfamily members include leukocyte common antigen-related (LAR) protein (encoded by Ptprf) ${ }^{57}$ which was up-regulated in both the intracellular (1.9-fold) and extracellular (1.9-fold) fraction. Gram positive pathogens and commensal bacteria can interact with fibronectin. ${ }^{58}$ Binding to fibronectin seems to be facilitated by sugar-binding domains of the pili since enzymatic deglycosylation of fibronectin significantly reduced adhesion of recombinant $L$. lactis strains expressing the pil2 and pil3 gene clusters of B. bifidum PRL2010. ${ }^{59}$ Proteins involved in immunity were also altered in the BCF-treated HT-29 cells. Lipocalin 2 (LCN2), a siderophore-binding antimicrobial glycoprotein, in order to prevent bacterial uptake of iron, binds to siderophores, which is critical for the control of infection. ${ }^{60}$ Singh et al. ${ }^{61}$ reported that Lcn2 expression is regulated by microbiota-induced MyD88 signaling, which permits fast robust induction of this protein under a range of challenges which in turn aids in keeping microbiota in check. Manipulation of Lcn2 levels (levels in the intracellular and extracellular fraction of the HT-29 cells increased by 3.1 and 1.9 respectively) by BCF may similarly provide a strategy for management of the gut microbiota.

Cathepsins (CTS) are among the most investigated class of proteases $^{62}$ and undergo post-translational modification with the mature protein being glycosylated. ${ }^{63}$ They operate in many cell functions such as pathogen killing, protein processing, apoptosis, antigen presentation, and tissue remodelling. ${ }^{.4}$ Several studies have shown the ability of cathepsin B to degrade ECM either intracellularly, extracellularly, or both. ${ }^{65,66}$ Interestingly, of CTSA (-2.1-fold), CTSB -1.8 -fold) and CTSC (-1.7-fold) were evident in the extracellular fraction of the BCF treated HT-29 cells. Considering protease inhibitors, 
(A)

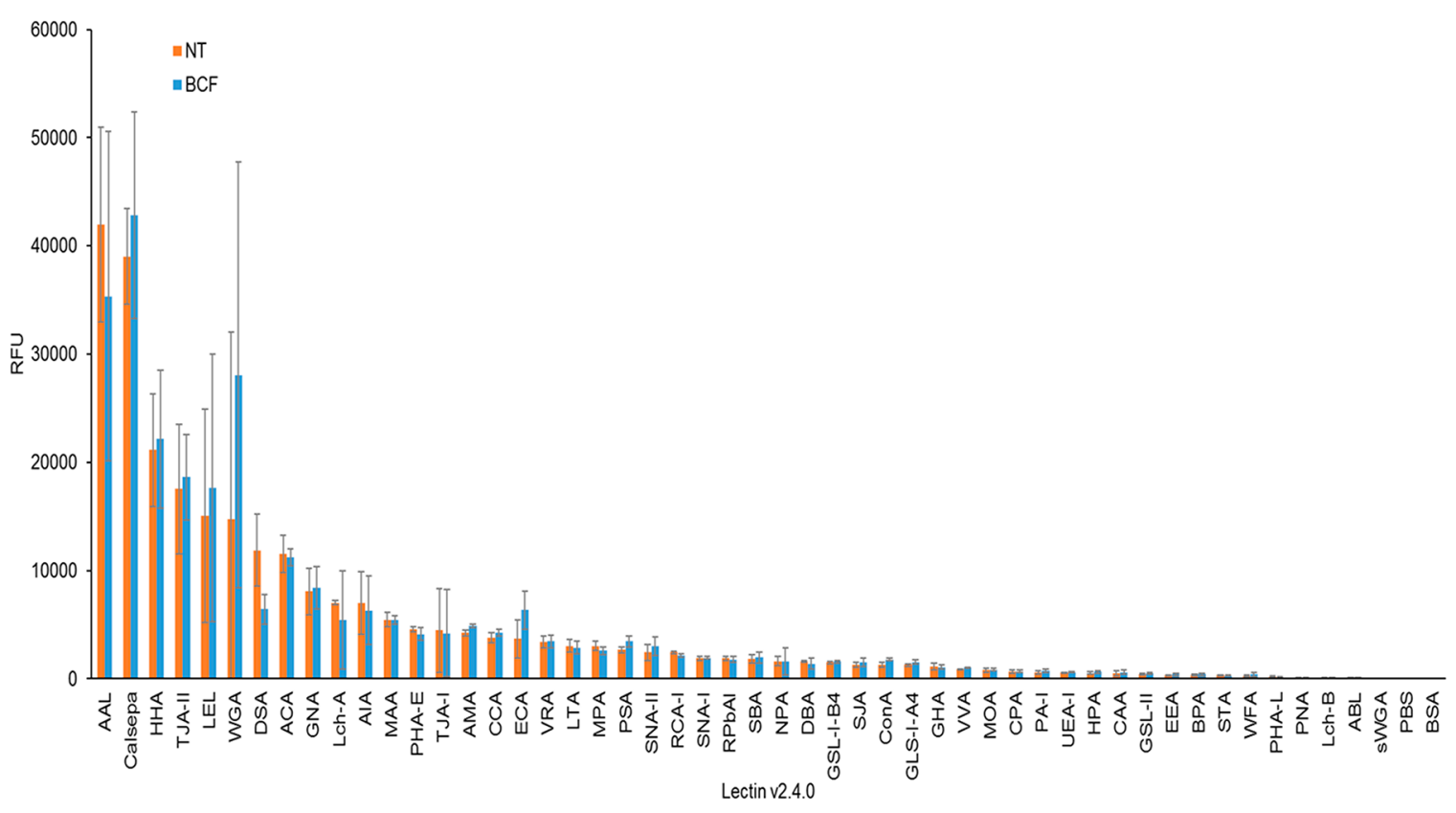

(B)

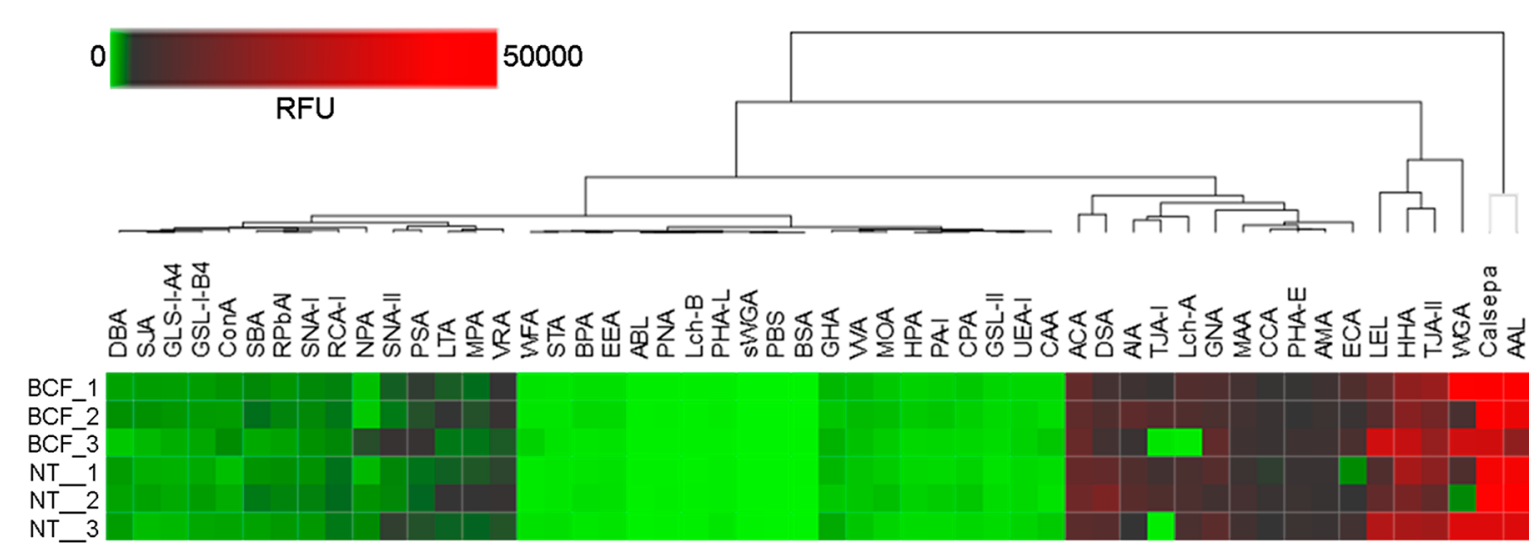

(C)

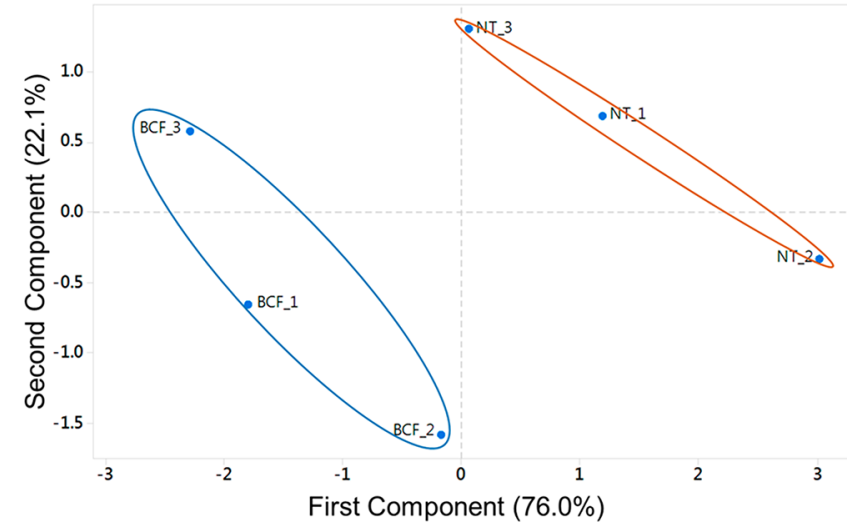

Figure 4. Lectin microarray profiles for HT-29 cell surface glycoproteins. Bar chart (A) of mean lectin microarray responses ( $n=3)$ for HT-29 proteins without (NT) and after exposure to BCF. Responses ranked by intensity and error bars represent \pm 1 standard deviation. Heat map (B) of replicate profiles (NT_1-3; BCF_1-3) with the lectin responses arranged by unsupervised hierarchical clustering. Score plot (C) generated for the first two components based on principal component analysis of responses from five lectins with $p<0.05$ (GSL-I-A4, $p=0.0229$; DSA, $p=0.0403$; RCA-I, $p=0.0129$; AMA, $p=0.0098$; and MPA, $p=0.0152$ ). 
almost all known serpins are glycosylated and are expressed at the mucosal surface and have been associated with the inhibition of HIV binding, replication, and reduction of inflammation of vulnerable cells. ${ }^{67}$ Maspin, encoded by SERPINB5, was uniquely detected in the extracellular fraction of BCF-treated cells even though it is an intracellular protein. ${ }^{68}$ Secreted Maspin is thought to bind to extracellular matrix components, such as collagen, and therefore influence the susceptibility of the matrix to proteolytic degradation in particular cathepsin D mediated degradation. ${ }^{69}$

Hepatocyte growth factor activator inhibitor type 1 (HAI-1) is a membrane-bound serine protease inhibitor expressed in epithelial tissues and is encoded by the serine protease inhibitor Kunitz type 1 (SPINT1) gene. Kawaguchi et al. ${ }^{70}$ demonstrated an essential role for HAI-1/SPINT1 in maintaining the integrity of colonic epithelium, and dysfunction of this inhibitor possibly enhances vulnerability to mucosal injury. HAI-1/SPINT1 regulates a number of membrane-associated cell surface serine proteases, with matriptase being the most associated target. Matriptase degrades extracellular matrix protein such as laminin and activates other cell surface proteases. ${ }^{71}$ The intestinal epithelial cells also express HAI-2/SPINT2, another membrane-bound Kunitz-type serine protease inhibitor, which has a comparable molecular structure to HAI-1/SPINT1. The HAI proteins are glycosylated $^{72}$ and higher levels of HAI-1/SPINT1 (1.7-fold) and HAI-2/SPINT2 (1.5) were evident in the extracellular fraction of BCF-treated cells suggesting degradation of certain extracellular matrix proteins may be reduced.

In eukaryotes, before glycosylation reactions can occur, the activated sugar must be transported into the Golgi or ER lumen where it can be availed of as a substrate by glycosyltransferases, a task undertaken by a family of transport proteins known as nucleotide sugar transporters. ${ }^{73}$ Membrane transporters, however, are not only the gatekeepers that regulate the influx and efflux of sugars but also other nutrients such as amino acids, trace minerals, vitamins, and electrolytes. Many of these transporters can themselves be glycosylated and BCF-treated cells had altered levels of several glycosylated solute carrier (SLC) transporters. CD98 (encoded by $S L C 3 A 2)$ is a type II transmembrane protein that covalently links to one of many L-type amino acid transporters (light chains) to form functional heterodimeric large neutral amino acid transport systems. ${ }^{74,75}$ This glycoprotein was up-regulated (1.5-fold) in the intracellular fraction. The SLC2A family of transporter proteins are crucial for the handling of hexoses and a variety of other substrates, ${ }^{76}$ and here SLC2A1 was upregulated (1.5-fold) in the presence of BCF. CTL2 (encoded by $S L C 44 A 2)$ is functionally expressed as a choline transporter ${ }^{77}$ and was uniquely detected in the intracellular fraction of the BCF-treated cells. Choline is also a known receptor target of both pathogenic ${ }^{78}$ and commensal bacteria. ${ }^{79}$ Another SLC (SLC39A10), with encodes the Zn transporter, ZIP10 was also differentially regulated with lower levels $(-2.1$-fold $)$ found in the extracellular fraction of the BCF-treated cells.

The biosynthesis of $\mathrm{N}$-glycans comprises the buildup of a conserved $N$-glycan structure linked to the lipid carrier: the lipid linked oligosaccharide (LLO) precursor and the ensuing transfer of this core structure to the designated sequons on newly synthetized glycoproteins as they are translocated into the endoplasmic reticulum (ER). ${ }^{80}$ In this study, BCF treatment lead to an increase in the levels of two glycosyltransferases involved in each phase of $\mathrm{N}$-glycan synthesis (Table 1). GDP-Man:Man3GlcNAc2-PP-dolicholalpha-1,2-mannosyltransferase, encoded by $A L G 11$, was upregulated (by 2.1-fold) and is important in the assembly of Dol-PP-oligosaccharides. ${ }^{81,82}$ Moving to Golgi-resident enzymes, a percentage of mammalian $N$-glycans can carry three GlcNAc branches, thereby yielding triantennary glycans. ${ }^{83}$ These third branches are initiated by alpha-1,3-mannosylglycoprotein 4-beta- $N$-acetylglucosaminyltransferase B (MGAT4B) which was only uniquely detected after BCF treatment. This indicates that small alterations to the terminal glycan chains of cell surface membrane and proteins may result after BCF treatment of the intestinal cells.

Lectin Microarray Profiling BCF Treated HT-29 Cell Surface Proteins. To further investigate differences in cell surface glycosylation after exposure to BCF, HT-29 cell surface proteins were subjected to lectin microarray profiling. Labeled preparations of the BCF-treated and the control cell (NT) proteins were first titrated onto microarray slides containing 50 immobilized lectins, each with well-characterized binding specificities. Through titration, a sample concentration was chosen to provide the best dynamic range and minimize nonspecific background interference. Following this, the fluorescently labeled samples underwent glycan profiling in triplicate. The data was used to investigate whether carbohydrate moieties had altered in quantity or presentation on the cell surface in response to the BCF in comparison to the NT samples. Profiles generated for the NT and BCF-treated HT-29 surface proteins exhibited substantial interaction with approximately two-thirds of the printed lectins (Figure 4a and b). Lectins which bound to the fluorescently labeled HT-29 proteins suggested a range of potential glycans were present which incorporated galactose (Gal), N-acetylgalactosamine (GalNAc), $N$-acetylglucosamine (GlcNAc), Gal- $\beta$ - $(1,4)$ GlcNAc (Type II LacNAc), 5- $N$-acetylneuraminic acid (Neu5Ac), mannose (Man), fucose, and complex, extended structures. No major pattern changes were observed for BCFtreated samples compared to the NT cells, but subtle, significant changes were observed at lectins GSL-I-A4, DSA, RCA-I, AMA, and MPA. For all replicates, mean binding intensity data from these five lectins was subjected to principal component analysis which verified the contributions of these responses to distinguish the profiles of nontreated (NT) and BCF treated HT-29 surface glycoproteins (Figure 4c).

The binding intensity at WGA increased in the BCF-treated cells compared to the control cells. WGA has reported affinity for both NeuAc and GlcNAc and has a preferred affinity for $\alpha$ 2,3-linked sialic acid over $\alpha$-2,6-linked sialic acids. ${ }^{84}$ MAA is known to be specific for $\alpha$-2,3-linked sialic acids ${ }^{85}$ and BCF exposure did not produce an intensity change at this lectin, suggesting the changes observed with WGA were the result of alterations in GlcNAc presentation or quantity and not due to sialic acid. Only low-level binding occurred with the lectin SNA-I, which is specific for $\alpha$-2,6-linked sialic acids. Although they are necessary for the assembly of oligosaccharides, expression of glycosyl transporters and transferases is not always correlated to specific glycosylation changes. The regulatory mechanisms of oligosaccharide alteration are complex and may also be driven by metabolic changes to pathways involved in sugar interconversion and processing. For this reason, lectin microarrays were employed to further ascertain if the glycosyltransferase expression observed in response to the BCF translated to the actual terminal glycans present on the HT-29 cells. The lectin microarray profiles 
generated for NT and BCF-treated cells showed only subtle differences between experimental conditions which suggested that any impact of the differential glyco-enzyme expression did not radically change the surface presentation of the cells in vitro. However, it is important to note that, in vivo, cell polarity may contribute to the concentrated positioning of glycosylated proteins on surfaces facing into the intestinal lumen or toward adjacent cells. In the in vitro environment, such polarization behavior could potentially be suppressed relative to the natural environment. Thus, the severity of global alterations in the HT-29 surface glycome may have been less sharply defined than they might be on apical surfaces in vivo owing to a variety of factors. Another possibility is that substantial changes could have been associated with fully secreted glycoproteins including some mucins, which would not have been profiled in the hydrophobic fraction representing the HT-29 surface glycoproteome.

Overall, it can be concluded that the changes induced in HT-29 cells due to treatment with BCF could be associated with only a modest overall change in the glycosylation pattern of the intestinal cells. While the overall changes to glycosylation upon BCF exposure were small, slight alterations could result in profound effects on the phenotype of these cells. The up-regulation and production of specific glycoproteins are contributing to an altered membrane cascade and, ultimately, a more preferable landscape for commensal bacteria to colonize as previously demonstrated. ${ }^{20}$ This study may also indicate the exact epitopes that commensal bacteria may exploit to colonize which, to date, has remained largely unknown. The glycan moieties which are present after treatment to the BCF and their overall pattern require further investigation as this is critical in understanding commensal preference for specific glycan moieties. The next step in this process is to chemically validate these lectins as the changes hypothesized may be through abundance and/or configuration and this can only be confirmed through chemical validation of the components.

As mentioned previously, there are limitations when using in vitro models such as the HT-29 cell line. The results obtained may not entirely reflect the in vivo situation and further progress must be made to determine whether intestinal glycosylation can be shaped by colostral components in animal models. Only a limited number of studies have been performed in animals where glycosylation patterns have been investigated and these are mainly focused on rodent or pig models $\left(\right.$ reviewed $\left.^{3}\right)$. For instance, sow-fed piglets had higher amounts of fucose $(48 \%)$ and glucosamine $(22 \%)$ in their colonic mucins when compared with artificially fed piglets. ${ }^{86}$ Malnutrition imposed upon rat pups through restricted access to suckling consequently resulted in an increase in sialic acid content and a reduced incorporation of 14C-Mannose, 14CGlcNAc, and 3H-Fucose into membranes compared with controls. ${ }^{87}$ Duncan et al. ${ }^{88}$ investigated the effects of milk oligosaccharides on the sialic acid utilization and synthesis pathways in neonatal rats. Interestingly, the level of colonic gene expression in the sialic acid synthesis pathway linked clearly with the levels of sialic acid present in the milk. The effects of premature and postponed weaning have been studied by Biol et al., who found that early weaning caused a decrease in the activity of sialyltransferase and an increase in fucosyltransferase activity. Yang et al. ${ }^{89}$ demonstrated that proteins involved in protein amino acid glycosylation, including mucin 13B, mucin-2, and glucosidase 2 subunit beta precursor, were down-regulated in weaning piglets, which indicated that weaning damaged the protective coating on the surface of intestine demonstrating the importance of milk in regulating the epithelial surface. It should be noted that while similar patterns exist in the animal gastrointestinal tract, there are also significant differences when compared with humans. For instance, in contrast to humans, fewer Core 3 and Core 4 glycans are found in the ileum and colon glycans of mice. ${ }^{90,91}$

The effect of diet on the intestinal surface and ultimately the microbes which can colonize the surface is now more widely understood at both the genetic and the proteomic level due to advances in technology allowing the complex molecular mechanisms to be characterized. The results of this study indicate that changes in the levels of glycoproteins and the glycosylation pattern of the intestinal cells are occurring in response to bovine colostrum. BCF exposure may result in less degradation of GAGS such as HS and glycosphingolipids such as GM2 along with increases in their abundance on the HT-29 cell surface. Other ECM proteins which contain domains which may interact with bacteria (e.g., fibronectin type III) are also increased in response to BCF. Certain glycosyltransferases involved in $\mathrm{N}$-glycan synthesis were also increased in the presence of BCF. This correlates with the results of the lectin array where slight increases in the signals at GalNAc- and GlcNAc-specific lectins were observed.

We hypothesize that this alteration in glycosylation leads to an advantageous cell surface for the colonization of commensal microbes. Whether other biological processes may also be contributing is yet to be determined. Our research provides new insights into the theory that diet may alter the intestinal surface through initiating changes in post-translational modifications. The exact component(s) of the BCF which may be responsible for the modification of the HT-29 cells still remains to be elucidated. Although further research is required to understand the complete mechanism of the BCF interaction with the intestinal cells, this study provides new insight into the modulatory activity of dietary components in the human GIT.

\section{ASSOCIATED CONTENT}

\section{Supporting Information}

The Supporting Information is available free of charge on the ACS Publications website at DOI: 10.1021/acs.jafc.8b06484.

Table S1.Lectins employed to monitor the dynamic glycosylation after HT-29 cells exposed with bovine colostrum fraction. Table S2. Intracellular proteins after LC-MS/MS analysis of HT-29 cells after exposure to the bovine colostrum fraction. Table S3. Extracellular proteins after LC-MS/MS analysis of HT-29 cells after exposure to the bovine colostrum fraction. (PDF)

\section{AUTHOR INFORMATION}

\section{Corresponding Author}

*E-mail: rita.hickey@teagasc.ie. Phone: +353 (0) 2542227. Fax: +353 (0) 2542340 .

ORCID

Jared Q. Gerlach: 0000-0001-7343-7201

Rita M. Hickey: 0000-0002-2128-2575

\section{Funding}

Sinead T. Morrin is in receipt of a Teagasc Walsh Fellowship. Quantitative mass spectrometry facilities were funded by a 
competitive infrastructure award from Science Foundation Ireland $[12 / \mathrm{RI} / 2346(3)]$.

\section{Notes}

The authors declare no competing financial interest.

\section{ACKNOWLEDGMENTS}

The authors wish to acknowledge Dr. Jonathan Lane for his insight and technical expertise.

\section{ABBREVIATIONS USED}

ATCC, American type culture collection; BCF, Bovine colostrum fraction; BP, Biological Processes; CC, Cellular Components; ECM, Extracellular Matrix; EPEC, Enteropathogenic Escherichia coli; FBS, Fetal bovine serum; GAGs, Glycosaminoglycans; GalNAc, N-Acetyl-D-galactosamine; GlcNAc, N-Acetyl-D-glucosamine; GO, Gene ontology; HS, Heparan sulfate; LC-MS/MS, Liquid chromatography with tandem mass spectrometry; MF, Molecular Functions; MS, Mass spectroscopy; MUC, Mucin; MWCO, Molecular weight cutoff; NT, nontreated control sample; TLRs, Toll-like receptors

\section{REFERENCES}

(1) Sassone-Corsi, M.; Raffatellu, M. No vacancy: how beneficial microbes cooperate with immunity to provide colonization resistance to pathogens. J. Immunol. 2015, 194 (9), 4081-7.

(2) Moran, A.; Gupta, A.; Joshi, L. Sweet-talk: role of host glycosylation in bacterial pathogenesis of the gastrointestinal tract. Gut 2011, 60, 1412.

(3) Kavanaugh, D.; O'callaghan, J.; Kilcoyne, M.; Kane, M.; Joshi, L.; Hickey, R. M. The intestinal glycome and its modulation by diet and nutrition. Nutr. Rev. 2015, 73 (6), 359-375.

(4) Pieper, R.; Kröger, S.; Richter, J. F.; Wang, J.; Martin, L.; Bindelle, J.; Htoo, J. K.; von Smolinski, D.; Vahjen, W.; Zentek, J. Fermentable fiber ameliorates fermentable protein-induced changes in microbial ecology, but not the mucosal response, in the colon of piglets-3. J. Nutr. 2012, 142 (4), 661-667.

(5) Tudela, C. V.; Boudry, C.; Stumpff, F.; Aschenbach, J. R.; Vahjen, W.; Zentek, J.; Pieper, R. Down-regulation of monocarboxylate transporter 1 (MCT1) gene expression in the colon of piglets is linked to bacterial protein fermentation and pro-inflammatory cytokine-mediated signalling. Br. J. Nutr. 2015, 113 (4), 610-617.

(6) Kaur, M.; Kaur, J.; Ojha, S.; Mahmood, A. Dietary fat effects on brush border membrane composition and enzyme activities in rat intestine. Ann. Nutr. Metab. 1996, 40 (5), 269-276.

(7) Mastrodonato, M.; Mentino, D.; Portincasa, P.; Calamita, G.; Liquori, G. E.; Ferri, D. High-fat diet alters the oligosaccharide chains of colon mucins in mice. Histochem. Cell Biol. 2014, 142 (4), 449459.

(8) Lenoir, D.; Greco, S.; Louisot, P. Implication of insulin and nutritional factors in the regulation of intestinal galactosyltransferase activity during postnatal development. Metab., Clin. Exp. 2000, 49 (4), 526-531.

(9) Babbar, H. S.; Jaswal, V. M.; Gupta, R.; Mahmood, A. Intestinal absorption of macromolecules and epithelial cell surface glycosylation in suckling rats nursed on mothers fed low-protein diet-I. Neonatology 2004, 58 (2), 104-111.

(10) Faure, M.; Moënnoz, D.; Montigon, F.; Mettraux, C.; Breuille, D.; Ballevre, O. Dietary threonine restriction specifically reduces intestinal mucin synthesis in rats. J. Nutr. 2005, 135 (3), 486-491.

(11) Barber, T.; Esteban-Pretel, G.; Marín, M. P.; Timoneda, J. Vitamin a deficiency and alterations in the extracellular matrix. Nutrients 2014, 6 (11), 4984-5017.

(12) Amit-Romach, E.; Uni, Z.; Cheled, S.; Berkovich, Z.; Reifen, R. Bacterial population and innate immunity-related genes in rat gastrointestinal tract are altered by vitamin A-deficient diet. J. Nutr. Biochem. 2009, 20 (1), 70-77.

(13) Jakaitis, B. M.; Denning, P. W. Human breast milk and the gastrointestinal innate immune system. Clin. Perinatol. 2014, 41 (2), 423-435.

(14) Kiela, P. R.; Ghishan, F. K. Physiology of intestinal absorption and secretion. Best Pract Res. Clin Gastroenterol 2016, 30 (2), 145159.

(15) Stelwagen, K.; Carpenter, E.; Haigh, B.; Hodgkinson, A.; Wheeler, T. T. Immune components of bovine colostrum and milk. J. Anim. Sci. 2009, 87, 3-9.

(16) King, T. P.; Begbie, R.; Slater, D.; McFadyen, M.; Thom, A.; Kelly, D. Sialylation of intestinal microvillar membranes in newborn, sucking and weaned pigs. Glycobiology 1995, 5 (5), 525-534.

(17) Lenoir, D.; Ruggiero-Lopez, D.; Louisot, P. Developmental changes in intestinal glycosylation: nutrition-dependent multi-factor regulation of the fucosylation pathway at weaning time. Biochim. Biophys. Acta, Biomembr. 1995, 1234 (1), 29-36.

(18) Angeloni, S.; Ridet, J. L.; Kusy, N.; Gao, H.; Crevoisier, F.; Guinchard, S.; Kochhar, S.; Sigrist, H.; Sprenger, N. Glycoprofiling with micro-arrays of glycoconjugates and lectins. Glycobiol 2004, 15 (1), 31-41

(19) Park, D.; Xu, G.; Barboza, M.; Shah, I. M.; Wong, M.; Raybould, H.; Mills, D. A.; Lebrilla, C. B. Enterocyte glycosylation is responsive to changes in extracellular conditions: implications for membrane functions. Glycobiology 2017, 27 (9), 847-860.

(20) Morrin, S.; Lane, J.; Marotta, M.; Bode, L.; Carrington, S.; Irwin, J.; Hickey, R. M. Bovine-Colostrum Driven of Intestinal Epithelial Cells for increased Commensal colonization. Appl. Microbiol. Biotechnol. 2019, In press.

(21) Held, G.; Grinstein, G.; Tu, Y. Relationship between gene expression and observed intensities in DNA microarrays-a modeling study. Nucleic Acids Res. 2006, 34 (9), e70-e70.

(22) Fu, X.; Fu, N.; Guo, S.; Yan, Z.; Xu, Y.; Hu, H.; Menzel, C.; Chen, W.; Li, Y.; Zeng, R. Estimating accuracy of RNA-Seq and microarrays with proteomics. BMC Genomics 2009, 10 (1), 161.

(23) Kobata, A.; Ginsburg, V.; Tsuda, M. Oligosaccharides of human milk. I. Isolation and characterization. Arch. Biochem. Biophys. 1969, 130 (1), 509-13.

(24) Lane, J. A.; O'Callaghan, J.; Carrington, S. D.; Hickey, R. M. Transcriptional response of HT-29 intestinal epithelial cells to human and bovine milk oligosaccharides. Br. J. Nutr. 2013, 110 (12), 212737.

(25) Saleh, A. A.; Jones, G. W.; Tinley, F. C.; Delaney, S. F.; Alabbadi, S. H.; Fenlon, K.; Doyle, S.; Owens, R. A. Systems impact of zinc chelation by the epipolythiodioxopiperazine dithiol gliotoxin in Aspergillus fumigatus: a new direction in natural product functionality. Metallomics 2018, 10 (6), 854-866.

(26) Collins, C.; Hurley, R.; Almutlaqah, N.; O’Keeffe, G.; Keane, T. M.; Fitzpatrick, D. A.; Owens, R. A. Proteomic characterization of Armillaria mellea reveals oxidative stress response mechanisms and altered secondary metabolism profiles. Microorganisms 2017, 5 (3), 60.

(27) Cox, J.; Hein, M. Y.; Luber, C. A.; Paron, I.; Nagaraj, N.; Mann, M. MaxLFQ allows accurate proteome-wide label-free quantification by delayed normalization and maximal peptide ratio extraction. Mol. Cell. Proteomics 2014, 13, 2513.

(28) Priebe, S.; Kreisel, C.; Horn, F.; Guthke, R.; Linde, J. FungiFun2: a comprehensive online resource for systematic analysis of gene lists from fungal species. Bioinformatics 2015, 31 (3), 445-6.

(29) Gerlach, J. Q.; Kilcoyne, M.; Joshi, L. Microarray evaluation of the effects of lectin and glycoprotein orientation and data filtering on glycoform discrimination. Anal. Methods 2014, 6 (2), 440-449.

(30) O’Riordan, N.; Gerlach, J. Q.; Kilcoyne, M.; O'Callaghan, J.; Kane, M.; Hickey, R. M.; Joshi, L. Profiling temporal changes in bovine milk lactoferrin glycosylation using lectin microarrays. Food Chem. 2014, 165, 388-96. 
(31) Corfield, A. Eukaryotic protein glycosylation: a primer for histochemists and cell biologists. Histochem. Cell Biol. 2017, 147 (2), 119-147.

(32) Zhang, X.; Wang, Y. Glycosylation quality control by the Golgi structure. J. Mol. Biol. 2016, 428 (16), 3183-3193.

(33) Hooper, L. V.; Gordon, J. I. Glycans as legislators of hostmicrobial interactions: spanning the spectrum from symbiosis to pathogenicity. Glycobiology 2001, 11 (2), 1R-10R.

(34) Gagnon, M.; Berner, A. Z.; Chervet, N.; Chassard, C.; Lacroix, C. Comparison of the Caco-2, HT-29 and the mucus-secreting HT29MTX intestinal cell models to investigate Salmonella adhesion and invasion. J. Microbiol. Methods 2013, 94 (3), 274-279.

(35) Cairns, M. T.; Gupta, A.; Naughton, J. A.; Kane, M.; Clyne, M.; Joshi, L. Glycosylation-related gene expression in HT29-MTX-E12 cells upon infection by Helicobacter pylori. World J. Gastroenterol 2017, 23 (37), 6817.

(36) Ringot-Destrez, B.; D’Alessandro, Z.; Lacroix, J.-M.; MercierBonin, M.; Leonard, R.; Robbe-Masselot, C. A sensitive and rapid method to determine the adhesion capacity of probiotics and pathogenic microorganisms to human gastrointestinal mucins. Microorganisms 2018, 6 (2), 49.

(37) Rousset, M. The human colon carcinoma cell lines HT-29 and Caco-2: two in vitro models for the study of intestinal differentiation. Biochimie 1986, 68 (9), 1035-40.

(38) Vogel, C.; Marcotte, E. M. Insights into the regulation of protein abundance from proteomic and transcriptomic analyses. Nat. Rev. Genet. 2012, 13 (4), 227.

(39) Huang, D. W.; Sherman, B. T.; Lempicki, R. A. Systematic and integrative analysis of large gene lists using DAVID bioinformatics resources. Nat. Protoc. 2009, 4 (1), 44.

(40) Mok, A.; Cao, H.; Hegele, R. A. Genomic basis of mucopolysaccharidosis type IIID (MIM 252940) revealed by sequencing of GNS encoding $\mathrm{N}$-acetylglucosamine-6-sulfatase. Genomics 2003, 81 (1), 1-5.

(41) Mukai, T.; Kaneko, S.; Matsumoto, M.; Ohori, H. Binding of Bifidobacterium bifidum and Lactobacillus reuteri to the carbohydrate moieties of intestinal glycolipids recognized by peanut agglutinin. Int. J. Food Microbiol. 2004, 90 (3), 357-362.

(42) Maita, N.; Tsukimura, T.; Taniguchi, T.; Saito, S.; Ohno, K.; Taniguchi, H.; Sakuraba, H. Human $\alpha$-L-iduronidase uses its own $N$ glycan as a substrate-binding and catalytic module. Proc. Natl. Acad. Sci. U. S. A. 2013, 110 (36), 14628-14633.

(43) Bartlett, A. H.; Park, P. W. Proteoglycans in host-pathogen interactions: molecular mechanisms and therapeutic implications. Expert Rev. Mol. Med. 2010, 12, 1 DOI: 10.1017/ S1462399409001367.

(44) Frantz, C.; Stewart, K. M.; Weaver, V. M. The extracellular matrix at a glance. J. Cell Sci. 2010, 123 (24), 4195-4200.

(45) Singh, B.; Fleury, C.; Jalalvand, F.; Riesbeck, K. Human pathogens utilize host extracellular matrix proteins laminin and collagen for adhesion and invasion of the host. FEMS Microbiol Rev. 2012, 36 (6), 1122-1180.

(46) Westermann, C.; Zhurina, D. S.; Baur, A.; Shang, W.; Yuan, J.; Riedel, C. U. Exploring the genome sequence of Bifidobacterium bifidum $\mathrm{S} 17$ for potential players in host-microbe interactions. Symbiosis 2012, 58 (1-3), 191-200.

(47) Fujita, M.; Kinoshita, T. GPI-anchor remodeling: potential functions of GPI-anchors in intracellular trafficking and membrane dynamics. Biochim. Biophys. Acta, Mol. Cell Biol. Lipids 2012, 1821 (8), 1050-1058.

(48) Chatterjee, S.; Mayor, S. The GPI-anchor and protein sorting. Cell. Mol. Life Sci. 2001, 58 (14), 1969-1987.

(49) Kinoshita, T.; Fujita, M.; Maeda, Y. Biosynthesis, remodelling and functions of mammalian GPI-anchored proteins: recent progress. J. Biochem. 2008, 144 (3), 287-294.

(50) Gordon, V. M.; Nelson, K. L.; Buckley, J. T.; Stevens, V. L.; Tweten, R. K.; Elwood, P. C.; Leppla, S. H. Clostridium septicum alpha toxin uses glycosylphosphatidylinositol-anchored protein receptors. J. Biol. Chem. 1999, 274 (38), 27274-27280.
(51) Fukushima, K.; Ikehara, Y.; Kanai, M.; Kochibe, N.; Kuroki, M.; Yamashita, K. A $\beta$ - $N$-acetylglucosaminyl phosphate diester residue is attached to the glycosylphosphatidylinositol anchor of human placental alkaline phosphatase: a target of the channel-forming toxin aerolysin. J. Biol. Chem. 2003, 278 (38), 36296-36303.

(52) Alegretti, A. P.; Mucenic, T.; Brenol, J. C. T.; Xavier, R. M. The role of $\mathrm{CD} 55 / \mathrm{CD} 59$ complement regulatory proteins on peripheral blood cells of systemic lupus erythematosus patients. Revista brasileira de reumatologia 2009, 49 (3), 276-287.

(53) Martín, R.; Martín, C.; Escobedo, S.; Suárez, J. E.; Quirós, L. M. Surface glycosaminoglycans mediate adherence between HeLa cells and Lactobacillus salivarius Lv72. BMC Microbiol. 2013, 13 (1), 210.

(54) García, B.; Fernández-Vega, I.; García-Suárez, O.; Castañón, S.; Quirós, L. M. The role of heparan sulfate proteoglycans in bacterial infections. J. Med. Microbiol Diag 2014, 3 (4), 1.

(55) Oh, E.-S.; Woods, A.; Lim, S.-T.; Theibert, A. W.; Couchman, J. R. Syndecan-4 proteoglycan cytoplasmic domain and phosphatidylinositol 4, 5-bisphosphate coordinately regulate protein kinase C activity. J. Biol. Chem. 1998, 273 (17), 10624-10629.

(56) Xu, Y.; Fisher, G. J. Receptor type protein tyrosine phosphatases (RPTPs)-roles in signal transduction and human disease. J. Cell Comm Sig 2012, 6 (3), 125-138.

(57) Streuli, M.; Krueger, N. X.; Hall, L. R.; Schlossman, S. F.; Saito, $\mathrm{H}$. A new member of the immunoglobulin superfamily that has a cytoplasmic region homologous to the leukocyte common antigen. J. Exp. Med. 1988, 168 (5), 1523-1530.

(58) Hymes, J. P.; Klaenhammer, T. R. Stuck in the middle: Fibronectin-binding proteins in gram-positive bacteria. Front. Microbiol. 2016, 7, 1504 .

(59) Turroni, F.; Serafini, F.; Foroni, E.; Duranti, S.; Motherway, M. O. C.; Taverniti, V.; Mangifesta, M.; Milani, C.; Viappiani, A.; Roversi, T. Role of sortase-dependent pili of Bifidobacterium bifidum PRL2010 in modulating bacterium-host interactions. Proc. Natl. Acad. Sci. U. S. A. 2013, 110 (27), 11151-11156.

(60) Guo, B. X.; Wang, Q. Q.; Li, J. H.; Gan, Z. S.; Zhang, X. F.; Wang, Y. Z.; Du, H. H. Lipocalin 2 regulates intestine bacterial survival by interplaying with siderophore in a weaned piglet model of Escherichia coli infection. Oncotarget 2017, 8 (39), 65386.

(61) Singh, T. P.; Malik, R. K.; Kaur, G. Cell surface proteins play an important role in probiotic activities of Lactobacillus reuteri. Nutrire 2016, 41 (1), 5.

(62) Turk, V.; Stoka, V.; Vasiljeva, O.; Renko, M.; Sun, T.; Turk, B.; Turk, D. Cysteine cathepsins: from structure, function and regulation to new frontiers. Biochim. Biophys. Acta, Proteins Proteomics 2012, 1824 (1), 68-88.

(63) Katunuma, N. Posttranslational processing and modification of cathepsins and cystatins. J. Signal Transduction 2010, 2010, 1.

(64) Conus, S.; Simon, H.-U. Cathepsins and their involvement in immune responses. Swiss Med. Wkly. 2010, 140, 1 DOI: 10.4414/ smw.2010.13042.

(65) Tu, C.; Ortega-Cava, C. F.; Chen, G.; Fernandes, N. D.; Cavallo-Medved, D.; Sloane, B. F.; Band, V.; Band, H. Lysosomal cathepsin B participates in the podosome-mediated extracellular matrix degradation and invasion via secreted lysosomes in v-Src fibroblasts. Cancer Res. 2008, 68 (22), 9147-9156.

(66) Cavallo-Medved, D.; Rudy, D.; Blum, G.; Bogyo, M.; Caglic, D.; Sloane, B. F. Live-cell imaging demonstrates extracellular matrix degradation in association with active cathepsin B in caveolae of endothelial cells during tube formation. Exp. Cell Res. 2009, 315 (7), $1234-1246$

(67) Aboud, L.; Ball, T. B.; Tjernlund, A.; Burgener, A. The role of serpin and cystatin antiproteases in mucosal innate immunity and their defense against HIV. Am. J. Reprod. Immunol. 2014, 71 (1), 1223.

(68) Teoh, S. S.; Whisstock, J. C.; Bird, P. I. Maspin (SERPINB5) is an obligate intracellular serpin. J. Biol. Chem. 2010, 285, 10862.

(69) Khalkhali-Ellis, Z.; Hendrix, M. J. Elucidating the Function of Secreted Maspin: Inhibiting Cathepsin D-Mediated Matrix Degradation. Cancer Res. 2007, 67 (8), 3535-3539. 
(70) Kawaguchi, M.; Takeda, N.; Hoshiko, S.; Yorita, K.; Baba, T.; Sawaguchi, A.; Nezu, Y.; Yoshikawa, T.; Fukushima, T.; Kataoka, H. Membrane-bound serine protease inhibitor HAI-1 is required for maintenance of intestinal epithelial integrity. Am. J. Pathol. 2011, 179 (4), 1815-1826.

(71) Kohama, K.; Kawaguchi, M.; Fukushima, T.; Lin, C.-Y.; Kataoka, H. Regulation of pericellular proteolysis by hepatocyte growth factor activator inhibitor type 1 (HAI-1) in trophoblast cells. Hum. Cell 2012, 25 (4), 100-110.

(72) Shimomura, T.; Denda, K.; Kawaguchi, T.; Matsumoto, K.; Miyazawa, K.; Kitamura, N. Multiple sites of proteolytic cleavage to release soluble forms of hepatocyte growth factor activator inhibitor type 1 from a transmembrane form. J. Biochem. 1999, 126 (5), 821828.

(73) Hadley, B.; Maggioni, A.; Ashikov, A.; Day, C. J.; Haselhorst, T.; Tiralongo, J. Structure and function of nucleotide sugar transporters: Current progress. Comput. Struct. Biotechnol. J. 2014, 10 (16), 23-32.

(74) Yan, Y.; Vasudevan, S.; Nguyen, H. T. T.; Merlin, D. Intestinal epithelial CD98: an oligomeric and multifunctional protein. Biochim. Biophys. Acta, Gen. Subj. 2008, 1780 (10), 1087-1092.

(75) Deves, R.; Boyd, C. Surface antigen CD98 (4F2): not a single membrane protein, but a family of proteins with multiple functions. $J$. Membr. Biol. 2000, 173 (3), 165-177.

(76) Long, W.; Cheeseman, C. I. Structure of, and functional insight into the GLUT family of membrane transporters. Cell Health Cytoskeleton 2015, 2015 (1), 167-183.

(77) Nakamura, T.; Fujiwara, R.; Ishiguro, N.; Oyabu, M.; Nakanishi, T.; Shirasaka, Y.; Maeda, T.; Tamai, I. Involvement of choline transporter-like proteins, CTL1 and CTL2, in glucocorticoidinduced acceleration of phosphatidylcholine synthesis via increased choline uptake. Biol. Pharm. Bull. 2010, 33 (4), 691-696.

(78) Bergmann, S.; Hammerschmidt, S. Versatility of pneumococcal surface proteins. Microbiology 2006, 152 (2), 295-303.

(79) Wang, R.; Jiang, L.; Zhang, M.; Zhao, L.; Hao, Y.; Guo, H.; Sang, Y.; Zhang, H.; Ren, F. The adhesion of Lactobacillus salivarius REN to a human intestinal epithelial cell line requires S-layer proteins. Sci. Rep. 2017, 7, 44029.

(80) Snider, M. D.; Rogers, O. C. Transmembrane movement of oligosaccharide-lipids during glycoprotein synthesis. Cell 1984, 36 (3), 753-761.

(81) Couto, J. R.; Huffaker, T. C.; Robbins, P. W. Cloning and expression in Escherichia coli of a yeast mannosyltransferase from the asparagine-linked glycosylation pathway. J. Biol. Chem. 1984, 259 (1), 378-382.

(82) Cipollo, J. F.; Trimble, R. B.; Chi, J. H.; Yan, Q.; Dean, N. The yeast ALG11 gene specifies addition of the terminal $\alpha 1$, 2-Man to the Man5GlcNAc2-PP-dolichol $N$-glycosylation intermediate formed on the cytosolic side of the endoplasmic reticulum. J. Biol. Chem. 2001, 276 (24), 21828-21840.

(83) Schachter, H. Biosynthetic controls that determine the branching and microheterogeneity of protein-bound oligosaccharides. Biochem. Cell Biol. 1986, 64 (3), 163-181.

(84) Kawashima, H.; Sueyoshi, S.; Li, H.; Yamamoto, K.; Osawa, T. Carbohydrate binding specificities of several poly- $\mathrm{N}$-acetyllactosamine-binding lectins. Glycoconjugate J. 1990, 7 (4), 323-334.

(85) Geisler, C.; Jarvis, D. L. Letter to the Glyco-Forum: Effective glycoanalysis with Maackia amurensis lectins requires a clear understanding of their binding specificities. Glycobiology 2011, 21 (8), 988-993.

(86) Turck, D.; Feste, A. S.; Lifschitz, C. H. Age and diet affect the composition of porcine colonic mucins. Pediatr. Res. 1993, 33 (6), 564-7.

(87) Jaswal, V. M.; Babbar, H. S.; Mahmood, A. Effect of malnutrition and hormone treatments on intestinal microvillus membrane glycosylation in suckling rats. Ann. Nutr. Metab. 1990, 34 (3), 155-62.
(88) Duncan, P. I.; Raymond, F.; Fuerholz, A.; Sprenger, N. Sialic acid utilisation and synthesis in the neonatal rat revisited. PLoS One 2009, 4 (12), No. e8241.

(89) Yang, H.; Xiong, X.; Wang, X.; Tan, B.; Li, T.; Yin, Y. Effects of weaning on intestinal upper villus epithelial cells of piglets. PLoS One 2016, 11 (3), No. e0150216.

(90) Holmen Larsson, J. M.; Thomsson, K. A.; Rodriguez-Pineiro, A. M.; Karlsson, H.; Hansson, G. C. Studies of mucus in mouse stomach, small intestine, and colon. III. Gastrointestinal Muc5ac and Muc2 mucin O-glycan patterns reveal a regiospecific distribution. Am. J. Physiol Gastrointest Liver Physiol 2013, 305 (5), G357-63.

(91) Thomsson, K. A.; Holmen-Larsson, J. M.; Angstrom, J.; Johansson, M. E.; Xia, L.; Hansson, G. C. Detailed O-glycomics of the Muc2 mucin from colon of wild-type, core 1- and core 3-transferasedeficient mice highlights differences compared with human MUC2. Glycobiology 2012, 22 (8), 1128-39.

(92) Moloney, N. M.; Owens, R. A.; Meleady, P.; Henry, M.; Dolan, S. K.; Mulvihill, E.; Clynes, M.; Doyle, S. The iron-responsive microsomal proteome of Aspergillus fumigatus. J. Proteomics 2016, 136, 99-111. 